\title{
The Contributions of Socioeconomic and Opioid Supply Factors to Geographic Variation in U.S. Drug Mortality Rates
}

\author{
Shannon M. Monnat*
}

\section{Working Paper No. 87}

January 2019

\begin{abstract}
Over the past two decades deaths from opioids and other drugs have grown to be a major U.S. population health problem, but the magnitude of the crisis varies across the U.S., and explanations for widespread geographic variation in the severity of the drug crisis are limited. An emerging debate is whether geographic differences in drug mortality rates are driven mostly by opioid supply factors or socioeconomic distress. To explore this topic, I examined relationships between county-level non-Hispanic white drug mortality rates for 2000-02 and 2014-16 and several socioeconomic and opioid supply measures across the urban-rural continuum and within different rural labor markets. Net of county

\footnotetext{
Lerner Center for Public Health Promotion in the Maxwell School of Citizenship and Public Affairs at
} Syracuse University. The author is grateful for financial support for this research from the Institute for New Economic Thinking (INET) and helpful suggestions from Thomas Ferguson of INET. This is a longer version of a revised paper in press at the Journal of Rural Studies (https://www.sciencedirect.com/science/article/pii/S0743016717312500).
\end{abstract}


demographic composition, average non-Hispanic white drug mortality rates are highest and increased the most in large metro counties. In 2014-16, the most rural counties had an average of 6.2 fewer deaths per 100,000 population than large metro counties.

Economic distress, family distress, persistent population loss, and opioid supply factors (exposure to prescription opioids and fentanyl) are all associated with significantly higher drug mortality rates. However, the magnitude of associations varies across the urbanrural continuum and across different types of rural labor markets. In rural counties, economic distress appears to be a stronger predictor than opioid supply measures of drug mortality rates, but in urban counties, opioid supply factors are more strongly associated with drug mortality rates than is economic distress. Ultimately, the highest drug mortality rates are disproportionately concentrated in economically distressed mining and service sector dependent counties with high exposure to prescription opioids and fentanyl.

\section{JEL Codes: I1, I3, J21, K32, R1.}

Keywords: health; mortality; urban-rural continuum; inequality; economic disadvantage; opioids 
Nationwide, mortality rates from drug overdoses and drug-induced diseases increased 200\%, from 6.8 to 20.8 deaths per 100,000 population between 1999 and 2016 (CDC, 2017a). The increase over this period was even more pronounced for non-Hispanic whites $(275 \%)$ who, except for American Indians, have the highest drug mortality rate of all major racial/ethnic groups, as of $2016^{1}$ (CDC, 2017a).

Over two-thirds of fatal drug overdoses involve opioids - prescription opioids, heroin, and fentanyl (Hedegaard et al., 2018a). Nationally, the cost of the opioid crisis, including health care, criminal justice, lost productivity, and value of lives lost is now estimated at $\$ 504$ billion annually, representing 2.8\% of GDP (White House Council of Economic Advisors, 2017). But opioids are not the only problem; deaths involving other drugs, such as cocaine, methamphetamine, and benzodiazepines (prescription anxiety medications) also increased over the past two decades (CDC, 2017a).

A common media and public health narrative around the contemporary U.S. drug crisis is that is has become disproportionately rural (Noonan, 2017; Runyon, 2017; van Vlaanderen, 2018), including the extreme claim that rural America is the new 'inner city' (Adamy and Overberg, 2017). This coverage, while bringing much needed attention to rural areas in distress, misrepresents the geography of drug overdose and ignores the tremendous heterogeneity in the severity of the drug crisis in rural areas (Rigg and Monnat 2018; Monnat, forth).

National surveillance studies show large geographic differences in U.S. drug mortality rates (Buchanich, et al. 2016; Mack, Jones, and Ballesteros, 2017; Monnat, 2018; Rossen, Khan and Warner, 2014). These surveillance studies provide an important first step in describing the

\footnotetext{
${ }^{1}$ In 2016, the age-adjusted mortality rate from all drug-induced causes (based on underlying cause of death) was 26.6 per 100,000 population for non-Hispanic whites, 18.2 for non-Hispanic blacks, 10.1 for Hispanics, 3.3 for Asians, and 26.3 for non-Hispanic American Indians/Alaska Natives (CDC 2017a).
} 
U.S. overdose crisis, but they do not delineate the mechanisms driving its geographic variation. In addition, when they do include a measure of metropolitan status, it is a binary rural/urban categorization that treats 'rural' as one homogenous category without considering broader variation in features of rural areas that may influence variation in rates, including socioeconomic conditions, labor market structure, and opioid supply factors. These limitations mask important within-rural variation in mortality rates, including heterogeneity in the remoteness of different rural places and across different types of rural labor markets.

The present study addresses these limitations and advances the research on urban-rural disparities in drug mortality by: 1) describing differences in county-level drug mortality rates across the urban-rural continuum; 2) determining whether differences are explained by socioeconomic and/or opioid supply factors, and 3) determining whether socioeconomic or opioid supply factors are equally important in explaining variation in drug mortality rates along the urban-rural continuum and within different types of rural counties.

\section{Urban-Rural Differences in Health and Mortality}

After decades of lower or nearly comparable all-cause mortality rates in rural than in urban areas, a rural mortality penalty emerged in the 1980s and has grown in each subsequent decade (Cosby et al., 2008). This trend reversal was due in part to higher rates of heart disease mortality in rural areas (Cossman, et al. 2010), but increases in fatal drug overdoses along with alcohol-related liver diseases and suicide have also contributed to the growing gap (Fontanella et al., 2015; Hedegaard et al., 2018b; Singh and Siahpush, 2014). In fact, increases in drug, alcohol, and suicide mortality (the so-called 'deaths of despair') among middle-age non-Hispanic whites 
have been so large as to reduce life expectancy overall for that group (Case and Deaton, 2015; Case and Deaton, 2017).

Studies on various health outcomes, including heart disease, obesity, self-rated health, suicide, all-cause mortality, and life expectancy (Call et al., 2000; Hedegaard et al., 2018b; James, 2014; James and Cossman, 2017; Monnat and Beeler Pickett, 2011; Morton, 2004; Satcher, 2001; Singh and Siahpush, 2014) find important differences across the urban-rural continuum (i.e., based on urban population size and adjacency to metropolitan areas) that are lost when binary measures are used and population size and metropolitan adjacency are not taken into account.

National research on prescription opioid misuse (Rigg and Monnat, 2015; Monnat and Rigg, 2016) and fatal drug overdoses generally finds comparable or slightly higher rates in urban than in rural counties (Buchanich et al., 2016; Mack, Jones and Ballesteros, 2017; Rossen, Khan, and Warner; 2014). However, simplified binary urban/rural comparisons can mask important differences across degrees of rurality and opportunity structures (James, 2014; Roberts et al., 2016). For example, although rates of opioid-related inpatient hospitalizations, emergency department visits, and mortality are high in some predominantly rural states (e.g., Maine, Kentucky, and West Virginia), they are comparatively low in other very rural states (e.g., Iowa, Nebraska, Idaho, and the Dakotas) (Keyes et al., 2014; Rigg et al., 2018), reflecting that the magnitude of the contemporary drug crisis varies substantially across the rural U.S.

To my knowledge, no existing studies explore the role of adjacency to metropolitan areas in contributing to within-rural differences in drug mortality rates. Adjacency to metropolitan areas can be viewed as a proxy for a variety of economic, social, health care supply, substance abuse treatment, and illicit drug market characteristics that may explain differential drug mortality across different rural places. In addition, labor market structure may be an important differentiator 
when considering the magnitude of the drug crisis across the rural U.S., especially given that labor markets vary across regions and have been differentially affected by both long- and shortterm economic downturns. Monnat (forthcoming) shows that, among rural counties, average opioid mortality rates are much higher among mining dependent counties (13.9 deaths per $100,000)$ and comparatively low among farming dependent counties (4.6 per 100,000).

\section{A Spatial Inequality Approach for Understanding the U.S. Drug Crisis}

The analyses that follow are framed within a subnational spatial inequality approach to understand spatial disparities in U.S. drug mortality rates. This approach situates the social processes of drug addiction and overdose within their spatial contexts by emphasizing the importance of shared place-level attributes in how social processes and the inequalities that follow unfold differently across the U.S. (Lobao et al., 2007). Both where individuals are located within geographic space (i.e., the spatially unequal distribution of vulnerable groups) and structural factors within geographic space are important to how inequalities emerge, operate, and change over time (Burton, et al. 2013; Lobao, 2004). Multiple forces have interacted to drive the rise in drug overdoses (Dasgupta et al., 2018). Below, I describe two specific spatially-relevant factors that may explain the widespread geographic inequality observed in recent drug deaths.

Socioeconomic distress. The social and economic factors that may be contributing to the opioid and larger drug crisis result from a long process of uneven development, industrial restructuring, and neoliberal policy approaches that have eroded economic stability for many groups in the U.S., especially those without a four-year college degree (NIH, 2018). The past three decades have witnessed historically massive changes in the U.S. economy, including but not limited to the 
Great Recession of the late 2000s. These economic changes have been inherently spatial, leading to economic decimation in some places and prosperity in others. Variation in labor market diversification and population composition made some places more vulnerable to the economic shifts that unfolded over the past three decades (Brown and Schafft, 2018; Lichter and Schafft, 2016). Employment restructuring led to the movement of many livable-wage production jobs (mining, manufacturing) out of places that depended on them and the concentration of high-wage high-skill service, finance, and technology-based employment in a small handful of urban cores (Bailey, et al., 2014; Brown and Swanson, 2003; Lobao, 2014; Peters, 2013; Smith and Tickamyer, 2011). This has resulted in fewer and lower-wage employment opportunities for individuals without a college degree. Many places previously characterized by dependence on manufacturing and mining employment are now dominated by precarious low-wage service work (Burton et al., 2013; Peters, 2012; Slack, 2014). Selective out-migration of the "best and brightest" (Carr and Kefalas, 2009), where healthier and better-resourced young adults leave poor communities to seek out better job opportunities, has intensified the disproportionate geographic clustering of multigenerational economic distress in many rural and urban areas alike.

The past-decade surge in drug deaths corresponds with significant, but spatially disparate, economic challenges, including increased working-age adult departure from the labor force, wage decline, and the increased geographic concentration of poverty (Iceland and Hernandez, 2017; Saez, 2016; Thiede, Kim, and Valasik, 2018). Research from both urban and rural sociology demonstrates that concentrated and sustained economic disadvantage can contribute to collective frustration and hopelessness, lower tax bases, community disinvestment, infrastructural decay, family disintegration, crime, and substance misuse (Brown and Swanson, 2003; Carr and Kefalas, 2009; McLean, 2016; Sampson and Groves, 1989; Smith and Tickamyer, 2011). As a result, a 
growing body of evidence shows strong associations between macro-level economic distress and poor mental health and substance abuse (Frasquilho et al., 2016; Galea, et al., 2003; Hempstead and Phillips, 2015; Kaplan et al., 2015; Kerr et al., 2017; Monnat, 2018; Pierce and Schott, 2017). For example, recent research from Charles, et al. (2018) shows that drug testing failure rates have increased steadily since the Great Recession. Hollingsworth et al. (2017) show that as the county unemployment rate increases by one percentage point, the opioid mortality rate increases by 3.6 percent. Krueger (2017) found that prime-age men who are not in the labor force experience notably lower levels of emotional well-being, derive relatively little meaning from their daily activities, and are more likely than working men to feel pain and take pain medication daily, all of which increase substance abuse and overdose risk (Ahmedani et al., 2017). Moreover, economic distress is often accompanied by family distress, like marital disintegration and multiple partner fertility (Burton et al., 2013), which are important distal risk factors for substance abuse (Ananat et al., 2017; Frasquilho et al., 2016).

As sociologist Emile Durkheim (1987/1966) showed over 120 years ago, during periods of serious social or economic upheaval, risk of disconnection from social institutions (anomie) increases, leading to higher rates of suicide. Along these lines, Case and Deaton $(2015,2017)$ have suggested that increases in drug overdose rates over the past two decades may be connected to distressed economic conditions and subsequent hopelessness and dislocation. Monnat (2018) has expanded this to suggest that geographic, not just temporal trends, in drug overdoses may be connected to these same forces. Employing the John Henryism and weathering hypotheses, Muennig et al. (2018) argue that chronic stressors and the sustained coping needed to survive them have cumulative long-term health effects. Such long-term stressors may place people at risk of self-medicating with opioids - substances that numb both physical and psychological pain. 
Opioid supply factors. Some scholars have questioned the "deaths of despair" or "distress" framing as an explanation for the surge in drug mortality rates and argue instead that the opioid crisis has been driven by changes to drug environments - namely the surge in prescription opioids throughout the late 1990s and 2000s - rather than economic or social conditions (Currie et al., 2018; Masters et al, 2017; Masters et al., 2018; Ruhm, 2018). Without question, opioid supply factors were an essential spark for the increase in fatal drug overdoses over the past two decades (Quinones, 2015). Others have already thoroughly described the processes that led to massive increases in opioid prescribing and consumption, including the push by patient advocacy groups to get pain recognized as the fifth vital sign, the emergence of OxyContin ${ }^{\circledR}$ (a potent extendedrelease opioid) in 1996, aggressive marketing by pharmaceutical companies to encourage physicians to use opioids to treat chronic pain, and pill mills (Kolodny et al., 2015; Van Zee, 2009), followed by increased availability of cheap heroin and fentanyl (Quinones, 2015). But these processes were not spatially random.

Opioid prescribing patterns have varied widely since the late 1990s (Paulozzi et al., 2014), with higher rates of prescribing among rural versus urban residents (Prunuske et al., 2014). Prescribing patterns are influenced by population composition, the culture of local healthcare system prescribing, and state policy. Compositionally, some places in the U.S., including many rural areas, are home to disproportionate shares of groups who are at risk of injury and disability and where the need for pain relief is high, including older adults, individuals in manual labor occupations, and military veterans (Van Gundy, 2006). OxyContin ${ }^{\circledR}$ and other strong opioids were heavily marketed in mining-dependent Appalachian communities long before they spread across the rest of the U.S. (Keyes et al., 2014; Quinones, 2015). Purdue Pharma, the producers of 
OxyContin ${ }^{\circledR}$, encouraged their sales reps to aggressively market to physicians in places where other opioids were already heavily prescribed (Van Zee, 2009). Purdue and other pharmaceutical companies targeted the lowest hanging fruit - the injured and jobless and people on disability and Medicaid in economically-decimated small cities and rural towns in Ohio, Kentucky, Tennessee, Virginia, and West Virginia (Macy, 2018; Quinones, 2015; Van Zee, 2009). In fact, with such close ties to the Appalachian region, OxyContin was once referred to as "hillbilly heroin" (Inciardi et al., 2009). While some physicians remained skeptical about prescribing opioids longterm and were fearful of addiction risk, others prescribed liberally. High-prescribing pain clinics (i.e., pill mills) - unregulated establishments where physicians provided prescriptions for OxyContin ${ }^{\circledR}$ and other opioids with little diagnosis or follow-up - proliferated in the most economically-depressed regions of the U.S. in the late 1990s (Quinones, 2015). By 2000, OxyContin ${ }^{\circledR}$ prescribing rates in West Virginia, eastern Kentucky, southwestern Virginia, and Alabama were 5 to 6 times higher than the national average (Van Zee, 2009).

As states cracked down on pill mills and implemented monitoring programs to reduce overprescribing, prescription opioids became more expensive and difficult to obtain. In addition, the reformulation of OxyContin ${ }^{\circledR}$ into an abuse-deterrent form in 2010 made OxyContin ${ }^{\circledR}$ more difficult to crush and inject. Recognizing the demand created by prescription opioids, Mexican drug cartels expanded their heroin business from California to small cities and towns throughout the middle and eastern U.S. (Quinones, 2015). Heroin, once largely an inner-city problem, is now routinely sold in many parts of suburban and rural America where it was once absent, due in large part to fluid and shifting boundaries between rural and urban areas (Lichter and Brown, 2014; Lichter and Ziliak, 2017) and what Burton et al. (2013 p. 1129) describe as the "new rural order - 
dramatic and rapid transformations in American rural life that are, in part, a consequence of growing economic interdependencies with urban centers."

A related factor that may help to explain geographic differences in drug mortality rates is spatially-disparate exposure to the powerful synthetic opioid fentanyl. Fentanyl is cheap and easy to smuggle into the U.S. in smaller quantities than heroin due to its potency (up to 50 times more potent than heroin). As a result, over the past three years there has been a major increase in the adulteration of heroin and other narcotics with fentanyl. Even when consumed in small quantities, fentanyl increases the likelihood of drug overdose compared with heroin, resulting in higher mortality rates. Most of the highest potency and purest fentanyl entering the U.S. comes via China through major shipping ports in New York and Chicago; fentanyl coming from Mexico is far less pure, and therefore less potent (C. Lau, personal communication, Nov. 15, 2018). Differences in a local drug market's exposure to highly-potent fentanyl surely contributes to geographic differences in recent drug mortality rates. Due to proximity to major shipping ports, persons who consume heroin and other narcotics in the northeast are at greater risk of consuming a product that has been adulterated with fentanyl, a risk that likely diminishes as the product makes its way through distribution networks that are more remote from large urban centers, where it may be "cut" or "stepped on" several times before reaching its final consumer.

Ultimately, geographic differences in the severity of the drug mortality crisis, including urban-rural continuum differences, may be driven by both socioeconomic and opioid supply factors. The subnational spatial inequality approach would suggest that these factors may be more important contributors to drug mortality in some types of places than others (Lobao, 2004), due to variation in population vulnerability and a variety of structural factors, including but not limited 
to local and state government policy, law enforcement response, social welfare expenditures, health care infrastructure, social infrastructure, and community cohesion.

In the analyses below, I examine the following research questions:

1) How do drug mortality rates differ along the U.S. urban-rural continuum?

2) Are differences explained by socioeconomic and/or opioid supply factors?

3) Are socioeconomic and/or opioid supply factors equally important in explaining variation in drug mortality rates across the different levels of the urban-rural continuum and within different types of rural counties?

\section{Data and Methods}

\section{Mortality}

Mortality data come from the restricted-use death certificate files from the National Center for Health Statistics National Vital Statistics System (NCHS, 2000-2016). These data identify causes of death and decedent county of residence from all death certificates filed in the U.S., enabling me to calculate county-level drug mortality rates (deaths per 100,000 population). Each death certificate contains a single underlying cause of death (UCD) and up to twenty contributing (i.e., multiple) causes. ${ }^{2}$ I categorized drug deaths based on the International Statistical Classification of Diseases, $10^{\text {th }}$ revision $(I C D-10)$ codes as any death that included an underlying or contributing cause (MCD) of accidental poisoning, intentional poisoning, poisoning of undetermined intent by exposure to drugs, drug-induced diseases, finding of drugs in the blood, and mental/behavioral disorders due to drugs. The specific ICD-10 codes are listed in the

\footnotetext{
${ }^{2}$ Each death is counted only once in these analyses. For example, if the death certificate listed ICD 10 codes for both accidental poisoning and finding of drugs in the blood, the death is counted once.
} 
Appendix A Table A1. In 2016 (the most recent year for which data are available), about $63 \%$ of drug-related deaths identified opioids on the death certificate. I included all drug-related codes and not just those that specify opioids because many death certificates do not identify the specific $\operatorname{drug}(\mathrm{s})$ involved, and opioid deaths are undercounted by an average of between $22 \%$ and $24 \%$ nationally, with widespread variation in the magnitude of underreporting across states (Ruhm, 2017). Moreover, about half of all drug overdoses involve more than one drug.

There are also important reasons for using the MCD versus UCD for these analyses. First, using the MCD reduces risk of undercounting deaths due to misclassification (Rockett et al., 2014). Second, identifying a single factor as the underlying cause of death is an oversimplification of clinical and pathological processes leading to death (Fedeli et al., 2015) and does not allow for the possibility that the death would not have occurred without the presence of drugs.

To smooth potentially large fluctuations from small changes in death counts in small population counties, I pooled deaths across the years 2014-16. Consistent with CDC methods, I then calculated age-adjusted rates using the 2000 U.S. standard population 10-year age groups for non-Hispanic whites. I restricted analyses to deaths among non-Hispanic whites to avoid conflating variation in racial composition with variation in drug mortality rates. Drug mortality rates are much lower among non-Hispanic blacks and Hispanics than among non-Hispanic whites. However, in supplemental analyses, I ran models on the overall drug mortality rate (not restricted to non-Hispanic whites). Results were overwhelmingly consistent.

Analyses are restricted to the 48 contiguous states and Washington, DC. I also excluded Broomfield County, CO because it did not become a county until 2001, and several of my covariates are for 2000. Mortality rates and U.S. Census Bureau variable estimates for counties with small populations are at risk of instability and large margins of error. Therefore, I also 
restricted analyses to counties with at least 1,000 non-Hispanic white adults in 2016. Based on these exclusion criteria, my analyses included 3,047 counties,

My analysis of county-level variation reflects the importance of counties as subnational socio-environmental units of analysis. Counties are small enough to reflect local economic and social conditions but also large enough to be meaningful for policy (Lobao et al., 2007). County governments provide political and economic structure, the county represents the context within which most social and health services are delivered and where most state funding for social programs is administered (Lobao, 2004; Lobao et al., 2007). Counties are also largely responsible for picking up the costs of the drug crisis, in the form of social service, criminal justice, and emergency service provider expenditures.

In the main analysis, I focused on understanding geographic variation in drug mortality rates for 2014-16. However, I also assessed change in drug mortality rates between 2000-02 and 2014-16 in supplemental analyses. The trends identified in the change models are nearly identical to those identified in the models predicting 2014-16 rates. The full results from the change models are presented in the Appendix C Tables C1-C3.

\section{Predictor Variables}

County metropolitan status is based on the USDA Economic Research Service's nine category Rural-Urban Continuum Codes (RUCC) for 2004 (USDA ERS, 2004). Average unadjusted mortality rates for each of the nine RUCC categories are presented in Appendix B Figure B1. I recategorized the nine original categories into five conceptually- and empiricallylogical categories. (1) Large metropolitan counties include RUCCs 1 and 2 and represent counties in metropolitan areas of 250,000 residents or more, (2) Small metropolitan counties includes 
RUCC 3 and represents counties in metropolitan areas with less than 250,000 residents, (3) Large nonmetropolitan counties that are adjacent to metropolitan areas include RUCCs 4 and 6, (4) Large nonmetropolitan counties that are not adjacent to metropolitan areas include RUCCs 5 and 7, (5) Rural counties include the remaining RUCCs, 8 and 9.

County-level socioeconomic measures came from the 2000 U.S. Decennial Census. I used data from 2000 rather than years that overlap the 2014-16 mortality rates to reduce reverse causality bias and allow for a lagged effect of predictors on mortality. Economic distress (2000) is measured with a standardized (z-score) factor-weighted index (alpha $=.875)$ that combines percent poverty, the ratio of state-to-county median household income, percentage of households receiving public assistance income, percentage age $25+$ without a four-year college degree, percent not-working (unemployed or not in the labor force), and percent with a work disability. These variables are consistent with those included in the Economic Innovation Group's Distressed Communities Index for zip codes (Fikri and Lettieri, 2018). I also tested the inclusion of the gini coefficient for income inequality and the percentage of renters spending more than 30 percent of household income on rent, but neither loaded highly on the economic distress factor. Family distress (2000), which is related to but distinct from economic distress, is measured with a standardized (z-score) index (alpha $=.780)$ that combines percent divorced or separated and percentage of families with children headed by a single parent. Persistent population loss is a binary measure indicating that the county population declined between both the 1980 and 1990 censuses and the 1990 and 2000 censuses. I included it as a proxy for resource supply, economic (dis)investment, and structural distress. It is also a proxy for residential mobility selection effects; counties with chronic out-migration are those from which the healthiest and most highlyresourced young adults often leave due to lack of educational and employment opportunities, 
thereby leaving behind concentrations of the least healthy, least resourced, and most vulnerable residents (Carr and Kefalas, 2009). Industry structure was based on the USDA ERS economic dependency classification for 2004, which identifies counties as dependent on farming, mining, manufacturing, public sector (i.e., government), service employment, or as non-specialized. These mutually exclusive categories are based on industry earnings and employment as a percentage of total labor, proprietors' earnings, and total employment in 1998-2000.

I included three measures of opioid supply. County-level opioid prescribing for 2009-2011 came from the CDC's compilation of county-level prescribing from QuintilesIMS Transactional Data Warehouse (CDC, 2018). These data report retail opioid prescriptions dispensed per 100 persons. A limitation to these data is that they include only prescriptions obtained from retail pharmacies and exclude high-volume prescribing pain clinics (i.e., "pill mills") where significant high frequency prescribing occurred - particularly in Appalachia and Florida. Prescribing data are available for 2006-2016. I used 2009-2011 rates because they represent years of peak prescribing, but in sensitivity analyses, I substituted rates for 2006-08 and 2012-14. Prescribing data were missing for $295(9.7 \%)$ of the counties included in these analyses. I conducted multiple imputation using the Markov chain Monte Carlo (MCMC) method to generate values for cases with missing data. To account for potential spillover effects from diversion across counties, I also included the average rate of opioid prescribing among neighboring counties. Neither of these variables were normally distributed, so I logged them before including them in regression models. Exposure to fentanyl is a state-level variable based on state reports of law enforcement encounters (drugs submitted for analysis) testing positive for fentanyl. Much of the increase in opioid deaths over the past three years is related to illicitly-manufactured fentanyl that is mixed with or sold as heroin or counterfeit pills - with or without the users' knowledge (CDC, 2016). Based on 2015 
data, the CDC classifies ten states as 'high fentanyl law enforcement encounter' states: Kentucky, Maine, Massachusetts, Maryland, New Hampshire, New Jersey, Pennsylvania, Ohio, Vermont, and Virginia (CDC 2016). I included a binary indicator to represent counties located in states with high exposure to fentanyl.

All models controlled for U.S. Census 2000 measures for county age composition (percent age $65+$ ), percent non-Hispanic white, and percent military veterans. In models that predicted change in the drug mortality rate, I also controlled for the county's drug mortality rate in 2000-02 to account for more or less rapid increases in counties that started the decade with higher rates. Preliminary models also included controls for county health care infrastructure (binary indicators for whether any part of the county was classified as a health care professional shortage area or mental health provider shortage area in 2010 , based on a formula derived by the U.S. Health Resources \& Services Administration. ${ }^{3}$ ) and physicians per capita. These variables were not statistically significant in any of the models, so I removed them to improve model fit. I also did not control for region, as it is highly collinear with fentanyl exposure, and in models stratified by metropolitan status region is collinear with labor market dependence. Ultimately, final variable selection was based on the research summarized above and assessment of multicollinearity and model fit.

\footnotetext{
${ }^{3}$ Ideally, I would have included indicators that capture the supply of mental health and substance abuse professionals and facilities, but those data are not available nationally at the county level. The Area Health Resource File captures county-level measures for specific types of health care providers (e.g., psychiatrists, psychologists, social workers, occupational, physical, and recreational therapists), but prior to the 2013-14 AHRF release, counties with missing values on any measures were designated with values of 0 , thereby making those measures unreliable because users are unable to identify which counties are missing vs. which counties truly have values of 0 on these measures. For more information, see User Documentation for the County Area Health Resource File 2015-2016 release, page 148. (https://datawarehouse.hrsa.gov/data/datadownload.aspx\#MainContent ct100_gvDD_lbl_dd topic ttl_0).
} 
Descriptive statistics for all variables included in the analysis are presented in Table 1. Descriptive statistics by urban-rural continuum are presented in Appendix Table A2.

\section{Analysis}

I begin by presenting maps showing county-level non-Hispanic white drug mortality rates for 2000-02 and 2014-16. I then proceed with results from the main regression analysis. To address RQ 1 and 2, I ran linear random effects regression models to account for the clustering of counties within states. Model residuals were normally distributed and diagnostic plots showed no potential heteroscedasticity problems, enabling me to keep mortality rates in their original linear form. Model 1 included only urban-rural continuum and controlled for age composition, percent non-Hispanic white, and percent military veterans. Model 2 added the socioeconomic measures. Model 3 introduced the opioid supply measures. Model 4 is the same as Model 3 but included random effects for economic distress and county opioid prescribing, allowing the associations between economic distress and mortality and prescribing and mortality to vary between states. Family distress random effects were not significant in preliminary models, so I did not include them in the final model.

To address RQ3, I first ran the fully-adjusted model from above stratified by urban-rural category to identify whether predictors of drug mortality rates vary across the continuum. I then restricted the analyses to nonmetro counties (RUCCs 4-9) and ran the fully-adjusted models stratified by USDA ERS labor market dependence to assess whether predictors of drug mortality rates varied across different types of rural economies. Random effects for economic distress and opioid prescribing were not significant in the stratified models, so I excluded them to optimize model fit 


\section{Spatial Models}

Exploratory data analysis revealed significant spatial autocorrelation in drug mortality rates (Moran's $I=0.397)$. To account for this spatial autocorrelation, spatial models are an alternative to multilevel models (MLMs). While MLMs account for the clustering of counties within states, they are unable to explicitly model the spatial processes driving the outcome of interest (i.e., they do not give us information about spillover effects on our outcome of interest across counties). Spatial models enable one to both account for and model spillover effects. Therefore in analyses that included all counties (i.e., not stratified by metro status), I tested a series of two-stage least squares spatial models that included (1) a spatial lag of the dependent variable $(\beta \mathrm{Wy}$, testing whether drug mortality rates are affected by drug mortality rates in neighboring counties), (2) spatial lags for the economic distress and opioid prescribing independent variables ( $\beta \mathrm{Wx}_{\mathrm{econ}}, \beta \mathrm{Wx}_{\mathrm{rx}}$, testing whether drug mortality rates are affected by spillover effects from economic distress and opioid prescribing in neighboring counties), and (3) a spatial error model $(\mathrm{I}-p \mathrm{~W})^{-1} \varepsilon$, that tested whether drug mortality rates are affected by the error from neighboring counties. Spatial error models account for correlated residuals (nonindependence) between neighboring counties by fitting the model with a correlation parameter of the residuals and are appropriate when there is reason to believe there are omitted variables in the residual that are likely to be similar among neighbors. The spatial weight matrix was based on first-order queens contiguity. I ran models both with and without state fixed effects. Because fentanyl exposure is a state-level variable, it is excluded from these models.

It would be inappropriate to run spatial models when stratifying by metropolitan status or labor market type. The omission of counties means that the spillovers from them are no longer 
included in the fitted model. For example, if we consider two adjacent counties (e.g., one metro and one nonmetro) and assume that the metro county is dropped from the analysis (as is the case in models that consider only nonmetro counties), the spillover from the dropped metro county to its nonmetro neighbor becomes 0 even though there really is spillover. That spillover becomes unobserved, thereby biasing the results. Therefore, I do not run spatial models for the stratified analysis. Instead, I attempt to account for spillover effects by including covariates that measure average values among neighboring counties. This does not adjust the model standard errors for spatial autocorrelation, as would be the case with spatially-explicit models, but it at least captures spillover effects across counties. To attempt to account for prescribing spillover effects, I included an indicator of average prescribing among neighboring counties. In preliminary analyses, I also included a covariate for the average value of economic distress and the average drug mortality rate among neighboring counties. These variables were not significant in the fully adjusted models, so I dropped them to maximize model fit.

Given that this paper's main focus is on stratification across the urban-rural continuum and by category of labor market dependence and for consistency in interpretation across all models, I report the results from the multilevel models, rather than the spatial models, in the main text. Tables and a brief discussion of findings from the spatial models are reported in Appendix D. Model results are nearly identical, and overall conclusions drawn are consistent between the multilevel and spatial models.

\section{Sensitivity Tests}

I conducted several sensitivity analyses. First, in lieu of modeling rates linearly, I modeled death counts (offset by the log of the non-Hispanic white population) using random effects negative binomial models. Appendix E Table E1 presents coefficients from these models. Second, 
I ran the fully adjusted model for all counties on the overall drug mortality rate (2014-16), not restricted to non-Hispanic whites (Appendix E Table E2). Coefficients for all variables are similar in magnitude and significance to the model predicting non-Hispanic white specific drug mortality rates. Results from the following additional sensitivity analyses are not presented but are available from the author upon request: Using the 2011-15 American Community Survey 5year estimates, I substituted temporally proximate predictor variables for the socioeconomic and demographic measures. These variables represent county conditions that overlapped with the deaths examined in this study rather than the conditions that prevailed in the decade prior to these deaths. I also ran models substituting opioid prescribing rates for 2006-08 and 2012-14. Third, I reran all models weighted by the log of the county non-Hispanic white population to give less weight to counties with smaller populations, and therefore more potential for measurement error. Fourth, I used an alternate version of urban-rural continuum based on the National Center for Health Statistics classification (CDC, 2017b). ${ }^{4}$ Finally, I ran models predicting opioid mortality specifically rather than all drug mortality. Findings were consistent across all of these alternative model specifications.

\section{Results}

\section{Geographic Differences in Drug Mortality Rates}

The average county non-Hispanic white drug mortality rate was 8.0 deaths per 100,000 population in 2000-02 $(\mathrm{std}=6.8, \min =0.0, \max =105.7)$ and 23.5 deaths per 100,000 in $2014-16$

\footnotetext{
${ }^{4}$ In the supplemental analysis using the NCHS urban-rural classification (CDC, 2017b), I collapsed counties as follows: (1) Large central metro are counties in metropolitan statistical areas (MSAs) of 1 million or more population that contain all or part of a principal city of the area (e.g., Los Angeles County, CA; Cook County, IL) (2) Large fringe metro are remaining counties in MSAs of one million or more. (3) Medium/small metro are counties in MSAs of $<1$ million population. (4) Micropolitan are nonmetropolitan counties that the Office of Management and Budget designates as belonging to a micropolitan statistical area. (5) Noncore are the remaining nonmetropolitan counties that do not belong to a micropolitan statistical area.
} 
$(\operatorname{std}=15.1, \min =0.0, \max =138.4)$, with an average increase of 15.5 deaths per 100,000 population over this period. As shown in Figure 1, there is substantial variation in rates between counties, with observable spatial clustering (Moran's I=0.397 in 2014-16). Local Indicators of Spatial Autocorrelation (LISA) maps (not shown), revealed above average mortality rate clusters for 2014-16 in southeastern New England, southwest Pennsylvania, the mid-Atlantic, central Appalachia, central Florida, southeastern Louisiana, eastern Oklahoma, parts of the Mountain West, Arizona, and southern and northern California. Below average rate clusters were observed in parts of New York and Virginia, the Mississippi Delta, Texas, and the north-central Plains.

In 2014-16, average mortality rates were highest among large metro counties at 26.7 deaths per 100,000 and lowest among rural counties at 18.5 deaths per 100,000 (see Appendix Table A2). Large metro counties also experienced a larger average increase in drug mortality than rural counties between 2000-02 and 2014-16 (17.3 vs. 12.5). However, there is more variation in both mortality rates in 2014-16 and the change in mortality rates among rural than among urban counties, reflected in the higher standard deviations for rural counties. In terms of socioeconomic and opioid supply differences along the urban-rural continuum, economic distress increases moving from most urban to most rural. Family distress is comparable for all but the most rural counties, where it is substantially lower than the other urban-rural categories. The most rural counties are characterized by labor markets dependent on farming. Most counties in the other urban-rural categories are either manufacturing dependent or non-specialized. Service dependence is more common in large metro counties than in the other urban-rural categories. Persistent population loss was most common among rural counties; 41 percent of rural counties are characterized as persistent population loss counties. Rates of opioid prescribing were highest in large nonmetro counties that are not adjacent to metro areas, followed by those that are adjacent 
to metro areas. Prescribing rates were the lowest in the most rural counties. Exposure to fentanyl is most common in large metro counties; nearly 25 percent of large metro counties are in 'high fentanyl law enforcement encounter' states. These percentages decline moving along the continuum from urban to rural.

Table 2 presents results from regression models predicting county-level non-Hispanic white drug mortality rates for 2014-16. All models control for year 2000 measures of percent age $65+$, percent non-Hispanic white, and percent military veterans. The null model (not shown), produced an intra-class correlation coefficient of 0.283 , indicating that about $28 \%$ of betweencounty variation in drug mortality rates is due to differences between states. I was able to account for two-thirds of that variance in the fully-adjusted model.

As shown in Model 1, mortality rates decline as we move from most urban to most rural, with 5.8 fewer drug deaths per 100,000 in the most rural compared to most urban counties. The introduction of socioeconomic measures in Model 2 actually increases the magnitude of the difference between large urban counties and rural counties, suggesting that rural counties would have even lower drug mortality rates if not for their higher average level of economic disadvantage. Both economic and family distress are associated with significantly higher drug mortality rates. In terms of labor market differences, mining and service dependent counties have significantly higher rates, and manufacturing and public sector (government) dependent counties have significantly lower rates than counties with non-specialized labor markets. Persistent population loss is also associated with significantly higher drug mortality rates.

Model 3 introduces opioid supply measures. Model 4 is the same except includes random slopes for economic distress and opioid prescribing. The findings are nearly identical across these two models. All three opioid supply measures are associated with significantly higher drug 
mortality rates; counties with higher rates of prescribing, higher average prescribing among neighbors, and that are in high fentanyl exposure states have higher drug mortality rates. The positive coefficient for average opioid prescribing among neighboring counties suggests important spillover effects that may represent prescription diversion across counties. The significant random effects for economic distress and opioid prescribing suggest that the relationships between these measures and drug mortality rates vary significantly across states; they are more important in some places than others. All the socioeconomic measures remained significant with the introduction of opioid supply measures, suggesting that the association between socioeconomic conditions and drug mortality rates is not explained by opioids supply factors.

As evidenced by the continued statistically significant differences in mortality along the urban-rural continuum, none of the variables included in the model explain why mortality rates are lower among small metro, large nonmetro, and rural counties compared to large metro counties. Net of demographic, socioeconomic, and opioid supply factors, small metro counties had 3.1 fewer deaths, large nonmetro counties adjacent to metro areas had 4.1 fewer deaths, large nonmetro counties not adjacent to metro areas had 5.4 fewer deaths, and rural counties had 6.2 fewer deaths per 100,000 population compared to large metro counties.

Results were very similar for models predicting change in mortality rates between 200002 and 2014-16 (shown in Appendix C, Table C1). In the fully adjusted model, small metro, large nonmetro (both adjacent and non-adjacent), and rural counties all had significantly smaller increases in drug mortality rates than large metro counties between 2000-02 and 2014-16. Economic and family distress, mining and service dependence, persistent population loss, opioid 
prescribing, and fentanyl supply were all associated with significantly larger increases in mortality rates.

\section{Predictors of Drug Mortality Rates Stratified by Urban-Rural Continuum}

Results from fully-adjusted models stratified by urban-rural continuum are presented in Table 3. Net of covariates, economic distress was associated with significantly higher drug mortality rates in all but small metro counties, but the magnitude of this relationship varied across the other urban-rural continuum categories.

Figure 2 shows the model-adjusted relationship between economic distress and drug mortality rates along the urban-rural continuum for varying levels of economic distress. As the figure shows, the relationship between economic distress and mortality is strongest among large nonmetro counties not adjacent to metro areas. Family distress was associated with significantly higher rates in large metro, large nonmetro not adjacent to metro, and rural counties. Persistent population loss was associated with higher rates in large and small metro counties and in large nonmetro counties not adjacent to metro areas.

Labor market type was differentially associated with mortality across urban-rural categories (see Figure 3). Large metro counties with labor markets dependent on manufacturing and public sector (government) employment have significantly lower drug mortality rates, and service dependent counties have significantly higher mortality rates compared to non-specialized counties. Among small metro counties, those dependent on mining are at a large disadvantage; at an average of 38.2 deaths per 100,000 (holding all else constant), the average drug mortality rate in small metro mining dependent counties is nearly $63 \%$ higher than the national rate of 23.5 . Service dependence was associated with significantly higher mortality rates in small metro 
counties as well. Among large nonmetro counties adjacent to metro areas, mining and service dependence were also associated with significantly higher mortality rates, whereas public sector dependence was associated with significantly lower rates. In large nonmetro counties not adjacent to metro counties, only mining dependence was associated with significantly higher rates. In rural counties, there were no significant differences in rates across different categories of labor market dependence. Overall, holding all else constant, mining dependent counties in small metro and large nonmetro counties that are adjacent to metro areas have the highest drug mortality rates. Public sector dependent counties in large nonmetro counties adjacent to metro areas and farming dependent rural and large nonmetro nonadjacent counties have the lowest drug mortality rates.

Opioid prescribing in 2009-11 was associated with significantly higher drug mortality rates across the urban-rural continuum, and average prescribing among neighboring counties was associated with higher mortality rates in all but rural counties. Fentanyl supply was significant only among metro counties (both large and small) and large nonmetro counties adjacent to metro areas. County-level variances from these models indicate that the models explain far less of the variation in drug mortality rates among rural counties than among metropolitan counties. This indicates that important factors are contributing to differences in drug mortality rates in rural areas that are not captured by these models.

As with the non-stratified models, models predicting change in rates between 2000-02 and 2014-16 were very similar across the models stratified by urban-rural continuum (see Appendix C Table C2).

Predictors of Drug Mortality Rates among Nonmetro Counties, Stratified by Type of Labor Market 
Finally, I assessed whether the socioeconomic and opioid supply predictors of drug mortality rates among nonmetro counties vary across different types of nonmetro areas, specifically as differentiated by their labor markets. Table 4 presents the results from fullyadjusted models (Appendix C Table C3 shows the models predicting change in rates, 2000-02 to 2014-16). Results show substantial variation in the degree to which socioeconomic and opioid supply factors relate to drug mortality rates across different nonmetro labor markets. Several specific differences are worth noting. First, among nonmetro counties, economic distress is associated with significantly higher mortality rates (2014-16) in mining dependent, service dependent, and non-specialized counties, but not in farming or public sector dependent counties. Second, family distress is associated with significantly higher mortality rates in farming, manufacturing, and non-specialized counties, but not in mining, service, or public sector (government) dependent counties. Persistent population loss is related to significantly higher mortality rates only in service dependent counties. Opioid prescribing is associated with significantly higher mortality rates in all but farming and service dependent counties. High fentanyl exposure is associated with higher mortality rates only in manufacturing and nonspecialized counties. Together, these models show that among nonmetro counties, drug mortality rates are highest in two particular types of places: economically distressed mining-dependent counties with high rates of opioid prescribing in the late 2000s and economically distressed service employment dependent counties characterized by persistent population loss.

\section{Discussion}

Consistent with recent research on fatal drug overdose trends in the U.S. (Buchanich et al., 2016; Monnat, 2018; Rossen et al., 2014), this study found significant geographic variation and 
spatial clustering in drug mortality rates (2014-16) and changes in mortality rates between 200002 and 2014-16. This is the first national study to simultaneously examine the contributions of both socioeconomic factors and opioid supply factors to geographic variation in drug mortality rates and to compare predictors of rates across the urban-rural continuum and within different types of rural counties. In so doing, this study identifies the characteristics of counties bearing the heaviest drug mortality burdens.

Analyses suggest several main conclusions. First, the current drug overdose crisis is not disproportionately rural. Average non-Hispanic white drug mortality rates (2014-16) are highest in large metro counties and decline precipitously as the continuum moves from more urban to more rural. In addition, rates have increased most in large metro counties and least in the most rural counties since the early 2000 . This finding was robust to alternate specifications of the urban-rural continuum. The average rural advantage in drug mortality rates found in this study is discordant with urban-rural research on a wide range of other health measures and behaviors. Research consistently shows that rural areas have worse self-rated health and higher prevalence of several chronic diseases, disability and functional limitations, chronic pain, injuries, psychological distress, physical inactivity, obesity, and smoking (Coben et al., 2009; Glasgow, Morton, and Johnson, 2004; Monnat and Beeler Pickett, 2011; Schiller et al., 2012) and that life expectancy declines precipitously along the continuum from most urban to most rural (Singh and Siahpush, 2014). Rural counties also have higher rates of alcohol-related and suicide mortality (Monnat, forth; Hedegaard et al., 2018b). As I will discuss shortly, however, average rural drug mortality rates mask considerable variation across different types of rural counties, some of which have among the very highest drug mortality rates in the U.S. 
Second, higher average mortality rates among metro counties are not explained by socioeconomic or opioid supply factors; urban-rural continuum coefficients remained significant and robust in fully-adjusted models. However, both socioeconomic and opioid supply factors are associated with significantly higher drug mortality rates. Nationally, counties characterized by more economic and family distress, dependence on mining or service employment, persistent population loss, higher rates of prescribing, proximity to high-prescribing counties, and counties located in states with high fentanyl exposure (mostly the northeast) have significantly higher drug mortality rates. Moreover, results from spatial autoregressive models showed that there are significant positive spillover effects for both neighboring counties' drug mortality rates and opioid prescribing rates. Importantly, the introduction of opioid supply measures to regression models did not eliminate the significance or magnitude of the economic factors, suggesting that economically distressed counties do not have higher drug mortality rates simply because they also have a bigger opioid supply problem.

However, a third important finding is that relationships between economic distress and mortality and between opioid supply and mortality vary in magnitude and significance across the U.S., something not considered in recent research arguing that the drug crisis is due predominantly to opioid supply factors (Currie et al., 2018; Ruhm, 2018). Conclusions drawn about the role of socioeconomic distress and opioid supply factors at the national scale cannot be assumed universally applicable across the U.S. This is evidenced by significant random effects for economic distress and opioid prescribing (the relationships between these variables and mortality rates vary significantly across states) and by differences in models stratified by urban-rural continuum and by labor market dependence. 
For example, economic distress is associated with higher drug mortality rates in large metro, but not small metro counties. Opioid supply is associated with higher drug mortality rates in both large and small metro counties. Economic distress and a county's opioid prescribing rate are associated with higher drug mortality rates across all three nonmetropolitan categories, but neither opioid prescribing among neighboring counties or location in a high fentanyl exposure state is associated with morality among the most rural counties. This finding may reflect less access to illicit drug markets in the most rural counties. In large nonmetro counties that are adjacent to metro areas, both higher prescribing among neighboring counties and fentanyl exposure are associated with significantly higher drug mortality rates. In addition to increasingly interdependent labor and transportation networks between urban and rural spaces (Lichter and Brown, 2014; Lichter and Ziliak, 2017), illicit drug markets may reflect an important type of interdependence.

In addition, findings from stratified models suggest that large drug mortality disparities across different types of rural labor markets play a critical role in understanding broader geographic patterns in drug mortality rates. Specifically, the drug mortality penalty is disproportionately concentrated in mining and service sector dependent counties. Economically distressed mining dependent counties with high rates of opioid prescribing in the late 2000s and economically distressed service sector dependent counties characterized by persistent population loss have much higher drug mortality rates than the national average. These important differences highlight rural heterogeneity, with different combinations of economic and opioid supply factors increasing the risk of high drug mortality rates. These findings suggest the need for caution when reporting average urban-rural differences in drug mortality rates; averages mask important variation in different types of rural areas. 
In terms of the clear disadvantage experienced within mining- and service-dependent counties, numerous in-depth accounts show that dependence on a declining industry and the economic instability, population loss, and disinvestments following job losses in that industry tend to overlap and be mutually reinforcing, manifesting in collective psychosocial distress, family and community breakdown, and social disorders like substance misuse (Alexander, 2017; Chen, 2015; Goldstein, 2017; Macy, 2018; McLean, 2016; Quinones, 2015; Reding, 2010; Sherman, 2009). In their recent research, Graham and Pinto (2018) found that poor rural whites are less hopeful and optimistic about their futures than any other group in the U.S. They suggest that people who are hopeful and optimistic about their future tend to invest in that future, whereas those with dampened hope may underinvest or simply give up. Many good-paying manufacturing jobs were replaced by low-wage and precarious service jobs throughout the 1980s and 1990s. Mining dependent counties in Appalachia have experienced pronounced and sustained declines in employment, wages, and population over the past several decades.

Of course, substance use problems are not new to Appalachia. As a response to untreated chronic pain and psychological distress manifesting from decades of intergenerational poverty, injury from physically grueling jobs, and lack of opportunity, residents of the most down-trodden parts of Appalachia have long self-medicated with alcohol and prescription and illicit substances (Keyes et al., 2014). The emergence of extended-release OxyContin ${ }^{\circledR}$ in 1996 escalated these long-term processes in places that were already vulnerable to opioids - drugs that numb both physical and psychological pain. Moreover, in places where unemployment and disability rates surged, OxyContin ${ }^{\circledR}$ became a form of currency; selling prescription opioids was viewed by some as the only viable way of paying the bills (Quinones, 2015; Macy, 2018). These actions are consistent with Ann Swindler's (1986) concepts of 'culture as a tool kit' or 'culture in action', 
wherein individuals deploy elements of their culture to inform their daily actions and behaviors. Culture is a dynamic set of processes structured by both external conditions and the characteristics of people living within a space at any given time. Swindler's concept of 'culture as a toolkit' can help us understand how certain constellations of structural conditions make selfmedicating with opioids or diverting (i.e., selling, trading, sharing) prescription opioids seem sensible in particular places at particular times.

As evidenced by the failure of the models to explain significant urban-rural variation in drug mortality rates and residual county-level variance, more research is needed to understand additional important contributors to geographic variation in drug mortality rates. One potential mechanism may be health-related measures, particularly those that reflect chronic pain and depression. Social capital may be another important unexplored factor. Opportunities for civic engagement facilitate social interaction, trust, goodwill, and social cohesion, and increase residents' sense of community belonging, potentially buffering against depression and substance misuse (Putnam, 2001). Overall, rural communities may be advantaged by their comparatively higher community attachment and social capital, but there is wide divergence in social capital across the U.S., with Midwestern farming dependent counties having much greater comparative social capital than other rural regions (Rupasingha et al., 2006).

\section{Limitations}

Findings should be considered in light of some additional limitations. First, analyses were ecologic and cannot account for decedents' characteristics, including duration of residence in the county of death. Second, death certificates may misclassify causes of death, and results may be 
biased by geographic heterogeneity in cause-of-death reporting, but using MCD files reduces the likelihood of undercounting due to misclassification (Rockett, Kapusta, and Coben, 2014). Third, heterogeneity within counties cannot be accounted for in these analyses. Many metropolitan counties have outlying rural areas with different population characteristics, labor market opportunities, and access to prescription and illicit drug markets than those in the urban core of the county. Moreover, urban-rural boundaries are highly fluid and shift over time, with significant interaction occurring in the urban-rural interface (Lichter and Brown, 2011; Lichter and Brown, 2014). Urban-rural boundary blurring means that people and communities regularly experience both urban and rural worlds, making distinct comparisons between them somewhat artificial (Lichter and Ziliak, 2017). Fourth, the available prescribing data include prescriptions from retail pharmacies only and exclude prescriptions that came from high-volume prescribing pain clinics (i.e., pill mills). This may lead to downward bias in the model coefficients for prescription opioid supply. The state-level law enforcement fentanyl encounter data is also a loose proxy for fentanyl exposure. As a result, the estimates for fentanyl exposure may be downwardly biased in these models. Fifth, associations between county environments and mortality rates likely play out over an extended period, but these analyses considered only relatively recent economic conditions and did not consider changes in environments over a longer period. Future research should examine the role of changing labor markets since the 1980s and concomitant county socioeconomic changes on drug mortality rates. Finally, it was beyond the scope of this paper to examine urbanrural variation in drug mortality rates across demographic subgroups (i.e., sex, race/ethnicity, age, educational attainment). Future research should be conducted to determine whether the urbanrural continuum differences and socioeconomic and opioid supply factors found to be important in this study apply equally to different demographic subgroups. 


\section{Conclusion}

Ultimately, the cliché that "addiction does not discriminate" ignores the fact that drug mortality rates vary significantly by geography and are disproportionately clustered among places characterized by higher prevalence of socioeconomic distress, disadvantaged labor markets, and greater access to opioids. The physiological processes that underlie addiction may not discriminate, but the factors that place individuals and communities at risk are not spatially random. Without a clear understanding of this geographic variation and without identifying the types of people and places at risk of high mortality rates, resources and policy solutions may be misdirected. The economic and social burdens of the U.S. drug crisis are substantial, and the places that are least equipped to do so are disproportionately carrying this burden. Funding to address the crisis (e.g., treatment, prevention, recovery) is often allocated on a population basis, resulting in underfunding the places in greatest need. Importantly, high rates of substance misuse, drug overdose, and their associated problems may repel the very community investments that could potentially improve economic conditions and quality of life, thereby contributing to a cycle of economic, social, and health decline.

National policy strategies cannot be assumed universally applicable. Counties are embedded within state contexts that can constrain or enhance local efforts to address the opioid and larger drug crisis. Understanding that certain combinations of socioeconomic factors and drug markets place some counties at greater risk of high drug mortality rates than others, and that similar risks are often shared by neighboring counties, could inform multijurisdictional and regional responses for better resource targeting (Brown and Shucksmith 2017; McLaughlin et al., 2007). 
Despite widespread media and political attention on drug overdoses (especially opioids), it is important to recognize that smoking and obesity remain the largest contributors to premature mortality, and combined rates from alcohol-induced deaths and suicides remain higher than the rate for drug-induced deaths. Further, in the current national obsession with opioids, the resurgence of methamphetamine has been largely marginalized or ignored altogether. Methamphetamine has long ravaged rural communities that have remained relatively immune to the opioid crisis, including in Iowa and Nebraska (Reding, 2009). Local reports suggest that methamphetamine may be overtaking heroin as the predominant drug problem in some places (Hernandez and Radnovich, 2018; Rezvani et al., 2018; Robles, 2018).

Moreover, it is unlikely than drugs, alcohol, and suicide exclusively capture 'despair'related deaths. Heart disease, diabetes, stroke, and cancer have decidedly proximate behavioral causes that may be related to distress, anxiety, despair, and weathering (e.g., poor diet, smoking, lack of exercise) (Hummer, 2018). Future research should examine whether the factors that best explain geographic variation in drug mortality are the same as those that explain geographic variation in other types of preventable behavior-related mortality.

Finally, although this study focuses on non-Hispanic whites, overall declines in wellbeing, health, and life expectancy in the U.S. over the past several years are not restricted to whites. As Muennig et al. (2018) argue, drug mortality increases among whites follow from crack and HIV epidemics among blacks, and both occurred within a context of already higher mortality rates and declines in well-being among Americans overall relative to people living in other wealthy post-industrial nations. In the current frenzy to get a tourniquet on the opioid epidemic, we must not lose sight of other large contributors to premature mortality and other enduring and emerging health crises among whites and nonwhites, alike. 


\section{References}

Adamy, Janet and Paul Overberg. 2017. Rural America is the New 'Inner City'. Wall Street Journal, May 26, 2017. Retrieved Nov. 18, 2018 https://www.wsj.com/articles/ruralamerica-is-the-new-inner-city-1495817008.

Ahmedani, B. K., E. L. Peterson, Y. Hu, R. C. Rossom, F. Lynch, C. Y. Lu, B. E. Waitzfelder, A. A. Owen-Smith, S. Hubley, D. Prabhakar, L. K. Williams, N. Zeld, E. Mutter, A. Beck, D. Tolsma and G. E. Simon. 2017. "Major Physical Health Conditions and Risk of Suicide." American Journal of Preventive Medicine 53(3):308-15. doi:

10.1016/j.amepre.2017.04.001.

Alexander, Brian. 2017. Glass House: The 1\% Economy and the Shattering of the All-American Town: Macmillian.

Ananat, E. O., A. Gassman-Pines, D. V. Francis and C. M. Gibson-Davis. 2017. "Linking Job Loss, Inequality, Mental Health, and Education." Science 356(6343):1127-28. doi: 10.1126/science.aam5347.

Bailey, Conner, Leif Jensen and Elizabeth Ransom, eds. 2014. Rural America in a Globalizing World: Problems and Prospects for the 2010s. Morgantown, WV: West Virginia University Press.

Brown, David L. and Louis E. Swanson. 2003. Challenges for Rural America in the Twenty-First Century. University Park, PA: Pennsylvania State University Press.

Brown, David L. and Kai A. Schafft. 2018. Rural People \& Communities in the 21st Century: Resilience \& Transformation, $2^{\text {nd }}$ edition. New York, NY: Wiley.

Brown, David L. and David Shucksmith. 2017. "Reconsidering Territorial Governance for Enhanced Rural-Urban Interdependence in America." ANNALS of the American Academy of Political and Social Science 672(1):282-301.

Buchanich, Jeanine M., Lauren C. Balmert, Janice L. Pringle, Karl E. Williams, Donald S. Burke and Gary M. Marsh. 2016. "Patterns and Trends in Accidental Poisoning Death Rates in the Us, 1979-2014." Preventive Medicine 89:317-23. doi: 10.1016/j.ypmed.2016.04.007.

Burton, Linda M., Daniel T. Lichter, Regina S. Baker and John M. Eason. 2013. "Inequality, Family Processes, and Health in the "New" Rural America." American Behavioral Scientist 57(8):1128-51. doi: 10.1177/0002764213487348.

Call, K.T., M.M. Casey, and T. Radcliff. 2000. "Rural Beneficiaries with Chronis Conditions: Does Prevalence Pose a Risk to Medicare Managed Care?" Managed Care Quarterly $8(3): 48-57$.

Carr, Patrick J. and Maria Kefalas. 2009. Hollowing out the Middle: The Rural Brain Drain and What It Means for America. Boston, MA: Beacon Press.

Case, Anne and Angus Deaton. 2015. "Rising Morbidity and Mortality in Midlife among White Non-Hispanic Americans in the 21st Century." Proceedings of the National Academy of Sciences 112(49):15078-83. doi: 10.1073/pnas.1518393112.

Case, Anne and Angus Deaton. 2017. "Morbidity and Mortality in the 21st Century." Vol. Brookings Papers on Economic Activity. The Brookings Institution.

Centers for Disease Control and Prevention. 2016. Reported Law Enforcement Encounters Testing Position for Fentanyl Increase across U.S. Retrieved Aug. 2, 2018 https://www.cdc.gov/drugoverdose/data/fentanyl-le-reports.html. 
Centers for Disease Control and Prevention. 2017a. National Center for Health Statistics. Underlying Cause of Death 1999-2016 on CDC WONDER Online Database, released December, 2017. Retrieved November 19, 2018 https://wonder.cdc.gov/.

Centers for Disease Control and Prevention. 2017b. NCHS Urban-Rural Classification Scheme for Counties. Retrieved November 18, 2018 https://www.cdc.gov/nchs/data access/urban rural.htm.

Centers for Disease Control and Prevention. 2018. U.S. Opioid Prescribing Rates. Retrieved May 6, 2018 https://www.cdc.gov/drugoverdose/maps/rxrate-maps.html.

Charles, Kerwin Kofi, Erik Hurst, and Mariel Schwartz. 2018. "The Transformation of Manufacturing and the Decline in U.S. Employment." Working Paper 24468. NBER Working Paper Series. Retrieved Nov. 18, 2018 http://www.nber.org/papers/w24468.

Chen, Victor Tan. 2015. Cut Loose: Jobless and Hopeless in an Unfair Economy: University of California Press.

Coben, Jeffrey H., Hope M. Tiesman, Robert M. Bossarte and Paul M. Furbee. 2009. "RuralUrban Differences in Injury Hospitalizations in the U.S., 2004." American Journal of Preventive Medicine 36(1):49-55. doi: 10.1016/j.amepre.2008.10.001.

Cosby, Arthur G., Tonya T. Neaves, Ronald E. Cossman, Jeralynn S. Cossman, Wesley L. James, Neal Feierabend, David M. Mirvis, Carol A. Jones and Tracey Farrigan. 2008. "Preliminary Evidence for an Emerging Nonmetropolitan Mortality Penalty in the United States." American Journal of Public Health 98(8):1470-2. doi: 10.2105/ajph.2007.123778.

Cossman, Jeralynn S., Wesley L. James, Arthur G. Cosby and Ronald E. Cossman. 2010. "Underlying Causes of the Emerging Nonmetropolitan Mortality Penalty." American Journal of Public Health 100(8):1417-19. doi: 10.2105/AJPH.2009.174185.

Currie, J., Jin, J.Y., \& Schnell, M. (2018). U.S. employment and opioids: Is there a connection? NBER Working Paper No. 24440. Retrieved Sept. 8, 2018 http://www.nber.org/papers/w24440.

Dasgupta, Nabarun, Beletsky, Leo, and Ciccarone, Daniel. 2018. "Opioid Crisis: No Easy Fix to its Social and Economic Determinants." American Journal of Public Health 108(2):182186.

Durkheim, Emile. 1987/1966. Suicide. New York: Free Press.

Fedeli, Ugo, Giacomo Zoppini, Carlo A. Goldoni, Franceso Avossa, Giuseppe Mastrangelo and Mario Saugo. 2015. "Multiple Causes of Death Analysis of Chronic Diseases: The Example of Diabetes." Population Health Metrics 13. doi: ARTN 2110.1186/s12963-0150056-y.

Fikri, Kenan and John Lettieri. 2018. "From Great Recession to Great Reshuffling: Charting a Decade of Change across American Communities." Economic Innovation Group: Washington, DC. Retrieved Nov. 18, 2018 https://eig.org/dci.

Fontanella, C. A., D. L. Hiance-Steelesmith, G. S. Phillips, J. A. Bridge, N. Lester, H. A. Sweeney and J. V. Campo. 2015. "Widening Rural-Urban Disparities in Youth Suicides, United States, 1996-2010." JAMA Pediatr 169(5):466-73. doi: 10.1001/jamapediatrics.2014.3561.

Frasquilho, D., M. G. Matos, F. Salonna, D. Guerreiro, C. C. Storti, T. Gaspar and J. M. Caldasde-Almeida. 2016. "Mental Health Outcomes in Times of Economic Recession: A Systematic Literature Review." BMC Public Health 16:115. doi: 10.1186/s12889-0162720-y. 
Galea, Sandro J., J. Ahern, and D. Vlahov. 2003. "Contextual Determinants of Drug Use Risk Behavior: A Theoretic Framework." J Urban Health 80(4 Suppl 3):iii50-8.

Glasgow, Nina, Lois Wright Morton and Nan E. Johnson, eds. 2004. Critical Issues in Rural Health. Ames, Iowa: Blackwell Publishing.

Goldstein, Amy. 2017. Janesville: An American Story. New York, NY: Simon \& Schuster.

Graham, Carol and Sergio Pinto. 2018. "Unequal hopes and lives in the USA: Optimism, Race, Place, and Premature Mortality." Journal of Population Economics 687(6).

Hedegaard, Holly, Arialdi M. Minino, and Margaret Warner. 2018a. Drug Overdose Deaths in the United States, 1999-2017. NCHS Data Brief 329: November 2018. Retrieved Dec. 6, 2018 https://www.cdc.gov/nchs/products/databriefs/db329.htm.

Hedegaard, H.., Curtin, S.C., and Warner, C. 2018. Suicide Mortality in the United States, 19992017. NCHS Data Brief 330: November 2018. Retrieved Dec. 6, 2018 https://www.cdc.gov/nchs/products/databriefs/db330.htm.

Hempstead, K. A. and J. A. Phillips. 2015. "Rising Suicide among Adults Aged 40-64 Years: The Role of Job and Financial Circumstances." Am J Prev Med 48(5):491-500. doi: 10.1016/j.amepre.2014.11.006.

Hernandez, L., and Radnovich, C. 2018. Oregon meth-related deaths higher than ever. U.S. News. Retrieved Sept. 7, 2018 https://www.usnews.com/news/best-states/oregon/articles/201802-24/oregon-meth-related-deaths-higher-than-ever.

Hollingsworth, Alex, Christopher J. Ruhm, and Kosali Simon. 2017. "Macroeconomic Conditions and Opioid Abuse.” NBER Working Paper No. 23192. Retrieved Nov. 18, 2018 https://www.nber.org/papers/w23192.

Hummer, Robert. 2018. “America's Population Health Crisis: Is it Really a Story of 'Deaths of Despair?' Keynote Address for Deep Wounds: Social Determinants of Health Inequalities, Cornell University, Ithaca, NY. Nov. 8, 2018.

Iceland, J. and E. Hernandez. 2017. "Understanding Trends in Concentrated Poverty: 1980-2014." Social Science Research 62:75-95. doi: 10.1016/j.ssresearch.2016.09.001.

Inciardi, J. A., H. L. Surratt, T. J. Cicero and R. A. Beard. 2009. "Prescription Opioid Abuse and Diversion in an Urban Community: The Results of an Ultrarapid Assessment." Pain Med 10(3):537-48. doi: 10.1111/j.1526-4637.2009.00603.x.

James, W. and J. S. Cossman. 2017. "Long-Term Trends in Black and White Mortality in the Rural United States: Evidence of a Race-Specific Rural Mortality Penalty." J Rural Health 33(1):21-31. doi: 10.1111/jrh.12181.

James, W. L. 2014. "All Rural Places Are Not Created Equal: Revisiting the Rural Mortality Penalty in the United States." Am J Public Health 104(11):2122-9. doi: 10.2105/ajph.2014.301989.

Kaplan, M. S., N. Huguet, R. Caetano, N. Giesbrecht, W. C. Kerr and B. H. McFarland. 2015. "Economic Contraction, Alcohol Intoxication and Suicide: Analysis of the National Violent Death Reporting System." Inj Prev 21(1):35-41. doi: 10.1136/injuryprev-2014041215.

Kerr, W. C., M. S. Kaplan, N. Huguet, R. Caetano, N. Giesbrecht and B. H. McFarland. 2017. "Economic Recession, Alcohol, and Suicide Rates: Comparative Effects of Poverty, Foreclosure, and Job Loss." Am J Prev Med 52(4):469-75. doi: 10.1016/j.amepre.2016.09.021.

Keyes, K. M., M. Cerda, J. E. Brady, J. R. Havens and S. Galea. 2014. "Understanding the RuralUrban Differences in Nonmedical Prescription Opioid Use and Abuse in the United 
States." American Journal of Public Health 104(2):E52-E59. doi:

10.2105/Ajph.2013.301709.

Kolodny, A., Courtwright, D. T., Hwang, C. S., Kreiner, P., Eadie, J. L., Clark, T. W., and Alexander, G. C. 2015. The Prescription Opioid and Heroin Crisis: A Public Health Approach to an Epidemic of Addiction. Annual Review of Public Health, 36(1), 559-574. doi:10.1146/annurev-publhealth-031914-122957

Krueger, Alan B. 2017. Where Have all the Workers Gone? An Inquiry into the Decline of U.S. Labor Force Participation.” Brookings Papers on Economic Activity. Retrieved Nov. 19, 2018 https://www.brookings.edu/wp-content/uploads/2017/09/1 krueger.pdf.

Lau, Christopher. 2018, November 15. Personal communication with Christopher Lau, Supervisory Special Agent, U.S. Department of Homeland Security, Homeland Security Investigations, JFK International Airport.

Lichter, Daniel T. and David L. Brown. 2011. "Rural America in an Urban Society: Changing Spatial and Social Boundaries." Annual Review of Sociology 37(1):565-92. doi: 10.1146/annurev-soc-081309-150208.

Lichter, Daniel T. and David L. Brown. 2014. "The New Rural-Urban Interface: Lessons for Higher Education." Choices Quater 1.

Lichter, Daniel T. and James P. Ziliak. 2017. "The Rural-Urban Interface: New Patterns of Spatial Interdependence and Inequality in America." The ANNALS of the American Academy of Political and Social Science 672(1):6-25. doi: 10.1177/0002716217714180.

Lichter, Daniel T. and Kai Schafft. 2016. "People and Places Left Behind: Rural Poverty in the New Century." Pp. 317-40 in The Oxford Handbook of the Social Science of Poverty, edited by D. B. Brady, L.M. : Oxford University Press.

Lobao, Linda. 2004. "Continuity and Change in Place Stratification: Spatial Inequality and Middle-Range Territorial Units." Rural Sociology 69(1):1-30. doi: $10.1526 / 003601104322919883$.

Lobao, Linda. 2014. "Economic Change, Structural Forces, and Rural America: Shifting Fortunes across Communities." Pp. 543-55 in Rural America in a Globalizing World: Problems and Prospects for the 2010s, edited by C. Bailey, L. Jensen and E. Ransom. Morgantown, WV: West Virginia University Press.

Lobao, Linda M., Gregory Hooks and Ann R. Tickamyer, eds. 2007. The Sociology of Spatial Inequality. Albany, NY: State University of New York Press.

Mack, K. A., C. M. Jones and M. F. Ballesteros. 2017. "Illicit Drug Use, Illicit Drug Use Disorders, and Drug Overdose Deaths in Metropolitan and Nonmetropolitan Areas United States." MMWR Surveill Summ 66(19):1-12. doi: 10.15585/mmwr.ss6619a1.

Macy, B. 2018. Dopesick: Dealers, Doctors, and the Drug Company that Addicted America. Little, Brown, and Company.

Masters, Ryan K., Andrea M. Tilstra, and Daniel H. Simon. 2018. "Explaining Recent Mortality Trends among Younger and Middle-Aged White Americans." International Journal of Epidemiology 47(1):81-88.

Masters, Ryan K., Andrea M. Tilstra, and Daniel H. Simon. 2017. "Mortality from Suicide, Chronic Liver Disease, and Drug Poisonings among Middle-Aged US White Men and Women, 1980-2013." Biodemography and Social Biology 63(1): 31-37.

McLaughlin, Diane K., C. Shannon Stokes, P. Johnelle Smith and Atsuko Nonoyama. 2007. "Differential Mortality across the United States: The Influence of Place-Based Inequality." 
in The Sociology of Spatial Inequality, edited by L. Lobao, G. Hooks and A. Tickamyer. Albany, NY: State University of New York Press.

McLean, K. 2016. "'There's Nothing Here": Deindustrialization as Risk Environment for Overdose." International Journal of Drug Policy 29:19-26. doi:

10.1016/j.drugpo.2016.01.009.

Monnat, Shannon M. Forthcoming. "Considering the Broader Context of the Opioid Crisis in Rural America: Trends, Causes, and Consequences." In Rural Families and Community, S. McHale, V. King, and J. Glick (Eds.). Springer.

Monnat, Shannon M. 2018. "Factors Associated with County-Level Differences in U.S. DrugRelated Mortality Rates." American Journal of Preventive Medicine, 54(5):611-619.

Monnat, Shannon M. and Camille Beeler Pickett. 2011. "Rural/Urban Differences in Self-Rated Health: Examining the Roles of County Size and Metropolitan Adjacency." Health \& Place 17(1):311-9. doi: 10.1016/j.healthplace.2010.11.008.

Monnat, Shannon M. and Khary K. Rigg. 2016. "Examining Rural/Urban Differences in Prescription Opioid Misuse among Us Adolescents." J Rural Health 32(2):204-18.

Morton, Lois Wright. 2004. "Spatial Patterns of Rural Mortality.” In N. Glasgow, N.E. Johnson, and L.W. Morton (Eds.), Critical Issues in Rural Health, Blackwell Publishing, Ames, IA

Muennig, Peter A., Reynolds, Megan, Fink, David S., Zafari, Z., and Geronimus, A.T. 2018. "America's Declining Well-being, health, and Life Expectancy: Not Just a White Problem." American Journal of Public Health 108(12): 1626-1631.

National Center for Health Statistics (NCHS). U.S. Detailed Mortality Micro Data, 2000-2016, as compiled from data provided by the 57 vital statistics jurisdictions through the Vital Statistics Cooperative Program. Hyattsville, MD.

National Institutes of Health (NIH). 2018. Full Summary - Contributions of Social and Behavioral Research in Addressing the Opioid Crisis. NIH HEAL Initiative. Retrieved Nov. 18, 2018 https://www.nih.gov/heal-initiative/full-summary-contributions-social-behavioralresearch-addressing-opioid-crisis.

Noonan, R. 2017. Rural America in crisis: the changing opioid overdose epidemic. Public Health Matters Blog. Centers for Disease Control and Prevention. Retrieved Sept. 7, 2018 https://blogs.cdc.gov/publichealthmatters/2017/11/opioids/.

Paulozzi, Leonard J., Karin A. Mack and Jason M. Hockenberry. 2014. "Variation among States in Prescribing of Opioid Pain Relievers and Benzodiazepines - United States, 2012." Journal of Safety Research 51(Supplement C):125-29. doi: https://doi.org/10.1016/j.jsr.2014.09.001.

Peters, David J. 2012. "Income Inequality across Micro and Meso Geographic Scales in the Midwestern United States, 1979-20091." Rural Sociology 77(2):171-202. doi: 10.1111/j.1549-0831.2012.00077.x.

Peters, David J. 2013. "American Income Inequality across Economic and Geographic Space, 1970-2010." Social Science Research 42(6):1490-504. doi: https://doi.org/10.1016/j.ssresearch.2013.06.009.

Pierce, Justin R. and Peter K. Schott. 2017. "Trade Liberalization and Mortality: Evidence from U.S. Counties." Vol. 2016-094. Finance and Economics Discussion Series. Washington, DC: Divisions of Research \& Statistics and Monetary Affairs, Federal Reserve Board.

Prunuske, J. P., C. A. St Hill, K. D. Hager, A. M. Lemieux, M. T. Swanoski, G. W. Anderson and M. N. Lutfiyya. 2014. "Opioid Prescribing Patterns for Non-Malignant Chronic Pain for 
Rural Versus Non-Rural Us Adults: A Population-Based Study Using 2010 Namcs Data." BMC Health Serv Res 14:563. doi: 10.1186/s12913-014-0563-8.

Putnam, Robert D. 2001. Bowling Alone: The Collapse and Revival of American Community. New York, NY: Touchstone Books.

Quinones, Sam. 2015. Dreamland: The True Tale of America's Opiate Epidemic: Bloomsbury Press.

Reding, Nick. 2010. Methland: The Death and Life of an American Small Town. New York, NY: Bloomsbury.

Rezvani, A., Martin, R., and Hajek, D. 2018. A new wave of meth overloads communities struggling with opioids. NPR. Retrieved Sept. 7, 2018 https://www.npr.org/sections/health-shots/2018/06/20/619929939/a-new-wave-of-methoverloads-communities-struggling-with-opioids.

Rigg, Khary K. and Shannon M. Monnat 2015. Urban vs. rural differences in prescription opioid misuse among adults in the United States: informing region specific drug policies and interventions. International Journal of Drug Policy, 26(5), 484-491.

Rigg, Khary K., Shannon M. Monnat, and Melody N. Chavez. 2018. Opioid-related Mortality in Rural America: Geographic Heterogeneity and Intervention Strategies. International Journal of Drug Policy 57:119-129. doi:10.1016/j.drugpo.2018.04.011.

Roberts, M. E., N. J. Doogan, A. N. Kurti, R. Redner, D. E. Gaalema, C. A. Stanton, T. J. White and S. T. Higgins. 2016. "Rural Tobacco Use across the United States: How Rural and Urban Areas Differ, Broken Down by Census Regions and Divisions." Health Place 39:153-9. doi: 10.1016/j.healthplace.2016.04.001.

Robles, F. 2018. Meth, the forgotten killer, is back. And it's everywhere. New York Times. Retrieved Sept. 7, 2018 https://www.nytimes.com/2018/02/13/us/meth-crystal-drug.html

Rockett, I. R. H., N. D. Kapusta and J. H. Coben. 2014. "Beyond Suicide Action Needed to Improve Self-Injury Mortality Accounting." JAMA Psychiatry 71(3):231-32. doi: 10.1001/jamapsychiatry.2013.3738.

Rossen, L. M., D. Khan and M. Warner. 2014. "Hot Spots in Mortality from Drug Poisoning in the United States, 2007-2009." Health Place 26:14-20. doi: 10.1016/j.healthplace.2013.11.005.

Ruhm, Christopher. 2017. "Geographic Variation in Opioid and Heroin Involved Drug Poisoning Mortality Rates." American Journal of Preventive Medicine 53(6):745-753.

Ruhm, Christopher. 2018. Deaths of despair or drug problem? NBER Working Paper No. 24188. Retrieved Sept. 8, 2018 http://www.nber.org/papers/w24188.

Runyon, Luke. 2017. Why is the opioid epidemic hitting rural America especially hard? NPR Illinois. Retrieved Sept. 7, 2017 http://www.nprillinois.org/post/why-opioid-epidemichitting-rural-america-especially-hard\#stream/0.

Rupasingha, Anil, Stephan J. Goetz and David Freshwater. 2006. "The Production of Social Capital in Us Counties." The Journal of Socio-Economics 35(1):83-101. doi: https://doi.org/10.1016/j.socec.2005.11.001.

Saez, Emmanuel and Gabriel Zucman. 2016. "Wealth Inequality in the United States since 1913: Evidence from Capitalized Income Tax Data." The Quarterly Journal of Economics 131(2):59. doi: 10.1093/qje/qjw004.

Sampson, Robert J. and W. Byron Groves. 1989. "Community Structure and Crime: Testing Social-Disorganization Theory." American Journal of Sociology 94(4):774-802. 
Satcher, D. 2001. The Surgeon General's Call to Action to Prevent and Decrease Overweight and Obesity, 2001. U.S. Department of Health and Human Services. Washington, DC.

Schiller, J. S., J. W. Lucas, B. W. Ward and J. A. Peregoy. 2012. "Summary Health Statistics for U.S. Adults: National Health Interview Survey, 2010." Vital Health Stat 10 (252):1-207.

Sherman, Jennifer. 2009. Those Who Work, Those Who Don't: Poverty, Morality, and Family in Rural America. Minneapolis, MN: University of Minnesota Press.

Singh, G. K. and M. Siahpush. 2014. "Widening Rural-Urban Disparities in Life Expectancy, U.S., 1969-2009." Am J Prev Med 46(2):e19-29. doi: 10.1016/j.amepre.2013.10.017.

Slack, Tim 2014. "Work in Rural America in the Era of Globalization." Pp. 573-90 in Rural America in a Globalizing World: Problems and Prospects for the 2010s, edited by C. Bailey, L. Jensen and E. Ransom. Morgantown, WV: West Virginia University Press.

Smith, Kristen E. and Ann R. Tickamyer. 2011. Economic Restructuring and Family Well-Being in Rural America. University Park, PA: The Pennsylvania State University Press.

Swinder, Ann. 1986. "Culture in Action: Symbols and Strategies." American Sociological Review 51(2):273-286.

Thiede, Brian, Hyojung Kim and Matthew Valasik. 2018. "The Spatial Concentration of America's Rural Poor Population: A Postrecession Update." Rural Sociology 83(1)

United States Department of Agriculture (USDA). Economic Research Service. Rural-Urban Continuum Code for Counties, 2004. Washington, DC.

van Vlaanderen, Zoe. 2018. What's behind the addiction crisis in rural America? National Council on Alcoholism and Drug Dependence, Inc. Retrieved Sept. 7, 2018 https://www.ncadd.org/blogs/addiction-update/what-s-behind-the-addiction-crisis-in-ruralamerica.

Van Zee, Art. 2009. The Promotion and Marketing of OxyContin: Commercial Triumph, Public Health Tragedy. American Journal of Public Health, 99(2), 221-227. doi:10.2105/AJPH.2007.131714

White House Council of Economic Advisors. 2017. The Underestimated Cost of the Opioid Crisis. Washington, DC. Retrieved Sept. 10, 2018 https://www.whitehouse.gov/briefingsstatements/cea-report-underestimated-cost-opioid-crisis/. 
Table 1. Variables Included in Regression Analysis with Summary Statistics

\begin{tabular}{|c|c|c|c|c|}
\hline \multirow[b]{2}{*}{ Variable } & \multicolumn{4}{|c|}{ Summary Statistics } \\
\hline & Mean/\% & SD & Min & Max \\
\hline Non-Hispanic white age-adjusted drug mortality rate, $2000-02$ & 8.0 & $(6.8)$ & 0.0 & 105.7 \\
\hline Non-Hispanic white age-adjusted drug mortality rate, 2014-16 & 23.5 & $(15.1)$ & 0.0 & 138.4 \\
\hline Change in drug mortality rate, $200-02$ to $2014-16$ & 15.5 & $(13.9)$ & -43.9 & 138.4 \\
\hline Economic Distress Index Measures, 2000 & 0.0 & $(1.0)$ & -3.1 & 5.2 \\
\hline Percent poverty & 14.0 & $(6.3)$ & 2.1 & 50.9 \\
\hline Ratio of state-to-county median household income & 117.3 & $(23.2)$ & 43.2 & 241.9 \\
\hline Percent households receiving public assistance income & 3.4 & $(1.8)$ & 0.4 & 16.5 \\
\hline Percent $\mathrm{w}<4$-year college degree & 83.5 & $(7.8)$ & 36.3 & 95.1 \\
\hline Percent not working & 42.4 & $(7.5)$ & 16.4 & 72.2 \\
\hline Percent with a work disability & 12.3 & $(3.3)$ & 3.7 & 25.9 \\
\hline Family Distress Index Measures, 2000 & 0.0 & $(1.0)$ & -3.2 & 4.0 \\
\hline Percent single-parent families & 11.3 & $(2.2)$ & 3.7 & 21.2 \\
\hline Percent divorced/separated & 26.1 & $(7.1)$ & 5.5 & 63.0 \\
\hline \multicolumn{5}{|l|}{ ERS Labor Market Dependence, 2004 (\%) } \\
\hline Farming & 13.1 & & & \\
\hline Mining & 4.0 & & & \\
\hline Manufacturing & 29.5 & & & \\
\hline Public (government) & 11.8 & & & \\
\hline Services & 10.9 & & & \\
\hline Non-specialized (reference) & 30.6 & & & \\
\hline Persistent population loss (1980 to 2000$)(\%)$ & 18.8 & & & \\
\hline Opioid prescriptions per 100 residents, 2009-2011 & 86.2 & $(49.8)$ & 0.2 & 556.8 \\
\hline Opioid prescriptions per 100 residents, 2009-2011 (logged) & 4.3 & $(0.7)$ & -1.6 & 6.3 \\
\hline Average opioid prescriptions among neighboring counties, 2009-11 & 72.7 & $(26.9)$ & 13.9 & 230.4 \\
\hline Average opioid prescriptions among neighboring counties, 2009-11 (logged) & 4.2 & $(0.4)$ & 2.6 & 5.4 \\
\hline County located in 'high fentanyl law enforcement encounter' state (\%) & 16.6 & & & \\
\hline
\end{tabular}


Percent non-Hispanic white, 2000

82.0

$\begin{array}{lll}(18.0) & 1.6 & 99.8\end{array}$

Percent veterans, 2000

13.9

$\begin{array}{lll}(2.8) & 3.3 & 33.2\end{array}$

Percent age $65+, 2000$

14.8

$\begin{array}{lll}\text { (4.1) } & 1.8 & 34.7\end{array}$

County $\mathrm{N}=3,047$; State $\mathrm{N}=49$

$\mathrm{SD}=$ standard deviation 

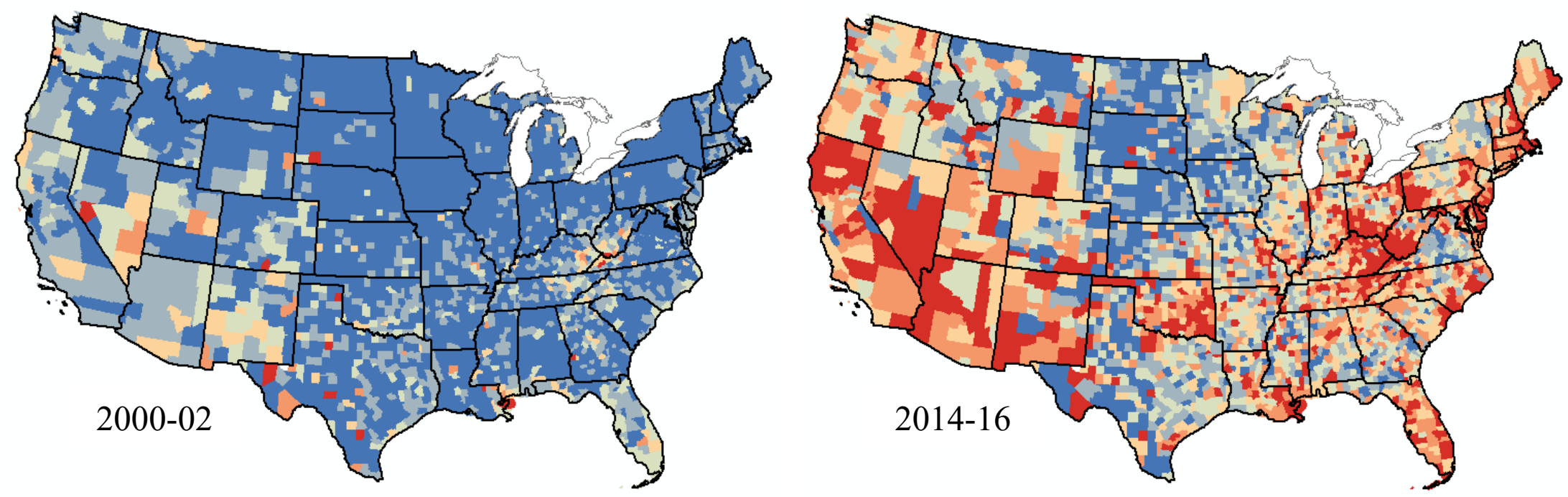

Deaths per 100,000 population

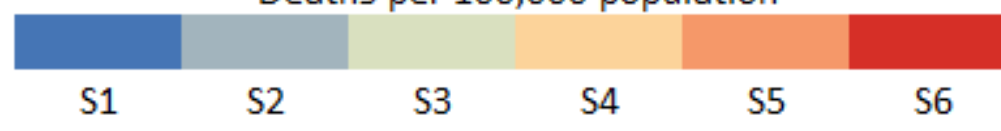

Figure 1. Non-Hispanic White Drug Mortality Rates, 2000-02 and 2014-16

Note: Rates are age adjusted. Sextiles for both maps are based on 2014-16 sextile values. Specific values cannot be presented due to NCHS data suppression requirements for counties with fewer than 10 deaths 
Table 2. Results from Multivariate Random Effects Regression on County-Level Non-Hispanic White Drug Mortality Rates, 2014-16

\begin{tabular}{|c|c|c|c|c|c|c|c|c|c|c|c|c|}
\hline \multirow[b]{2}{*}{ Predictor } & \multicolumn{3}{|c|}{ Model 1} & \multicolumn{3}{|c|}{ Model 2} & \multicolumn{3}{|c|}{ Model 3} & \multicolumn{3}{|c|}{ Model 4} \\
\hline & Est. & S.E. & & Est. & S.E. & & Est. & S.E. & & Est. & S.E. & \\
\hline Intercept & 27.35 & $(1.26)$ & $* * *$ & 28.46 & $(1.12)$ & $* * *$ & 26.60 & $(1.02)$ & $* * *$ & 26.16 & $(0.98)$ & $* * *$ \\
\hline \multicolumn{13}{|l|}{$\begin{array}{l}\text { Urban-Rural Continuum } \\
\text { (ref=Large metro) }\end{array}$} \\
\hline Small metro & -1.91 & $(0.84)$ & $*$ & -3.46 & $(0.82)$ & $* * *$ & -2.80 & $(0.80)$ & $* * *$ & -3.12 & $(0.79)$ & $* * *$ \\
\hline Large nonmet, adjacent to met & -2.25 & $(0.69)$ & $* *$ & -4.64 & $(0.71)$ & $* * *$ & -4.19 & $(0.70)$ & $* * *$ & -4.11 & $(0.69)$ & $* * *$ \\
\hline $\begin{array}{l}\text { Large nonmet, not adjacent to } \\
\text { met }\end{array}$ & -2.40 & $(0.82)$ & $* *$ & -5.93 & $(0.83)$ & $* * *$ & -5.67 & $(0.82)$ & $* * *$ & -5.39 & $(0.81)$ & $* * *$ \\
\hline Rural & -5.81 & $(0.88)$ & $* * *$ & -8.33 & $(0.93)$ & $* * *$ & -6.88 & $(0.92)$ & $* * *$ & -6.22 & $(0.91)$ & $* * *$ \\
\hline Economic distress, 2000 & & & & 3.69 & $(0.38)$ & $* * *$ & 2.75 & $(0.40)$ & $* * *$ & 2.70 & $(0.52)$ & $* * *$ \\
\hline Family distress, 2000 & & & & 3.25 & $(0.38)$ & $* * *$ & 2.45 & $(0.39)$ & $* * *$ & 2.57 & $(0.39)$ & $* * *$ \\
\hline \multicolumn{13}{|l|}{$\begin{array}{l}\text { Economic dependence, } 2004 \\
\text { (ref=non-specialized) }\end{array}$} \\
\hline Farming & & & & -0.11 & $(0.89)$ & & 0.37 & $(0.87)$ & & -0.11 & $(0.87)$ & \\
\hline Mining & & & & 7.48 & $(1.24)$ & $* * *$ & 7.27 & $(1.21)$ & $* * *$ & 6.30 & $(1.21)$ & $* * *$ \\
\hline Manufacturing & & & & -1.37 & $(0.61)$ & $*$ & -1.45 & $(0.60)$ & $*$ & -1.29 & $(0.59)$ & $*$ \\
\hline Public sector & & & & -1.83 & $(0.81)$ & $*$ & -1.76 & $(0.79)$ & $*$ & -1.70 & $(0.78)$ & $*$ \\
\hline Services & & & & 3.95 & $(0.88)$ & $* * *$ & 3.39 & $(0.86)$ & $* * *$ & 3.34 & $(0.85)$ & $* * *$ \\
\hline Persistent population loss & & & & 2.29 & $(0.70)$ & $* *$ & 2.12 & $(0.68)$ & $* *$ & 2.16 & $(0.68)$ & $* *$ \\
\hline Opioid prescribing (logged) & & & & & & & 2.09 & $(0.26)$ & $* * *$ & 2.62 & $(0.45)$ & $* * *$ \\
\hline $\begin{array}{l}\text { Avg. opioid prescribing of } \\
\text { neighboring counties (logged) } \\
\text { County located in 'high fentanyl }\end{array}$ & & & & & & & 2.37 & $(0.33)$ & $* * *$ & 2.26 & $(0.32)$ & $* * *$ \\
\hline law enforcement encounter' state & & & & & & & 6.89 & $(1.89)$ & $* * *$ & 6.83 & $(1.33)$ & $* * *$ \\
\hline \multicolumn{13}{|l|}{ Error Variance } \\
\hline County-Level Variance & 163.74 & $(4.23)$ & $* * *$ & 146.63 & $(3.80)$ & $* * *$ & 141.83 & $(3.67)$ & $* * *$ & 136.82 & $(3.58)$ & $* * *$ \\
\hline State-Level Variance & 61.43 & $(13.65)$ & $* * *$ & 38.96 & $(9.10)$ & $* * *$ & 22.82 & $(5.77)$ & $* * *$ & 21.46 & $(5.73)$ & $* * *$ \\
\hline Economic Distress & & & & & & & & & & 4.11 & $(1.61)$ & $* *$ \\
\hline Opioid Prescribing & & & & & & & & & & 3.48 & $(1.36)$ & $*$ \\
\hline
\end{tabular}


County $\mathrm{N}=3,047$; State $\mathrm{N}=49$

$\mathrm{S} . \mathrm{E} .=$ standard error; $* * * \mathrm{p}<.001 ; * * \mathrm{p}<.01 ; * \mathrm{p}<.05$; two-tailed tests

Null model: county-level variance $=168.40$, state-level variance $=66.3$, intraclass correlation coefficient $=0.283$

All models control for county age composition (2000), percent non-Hispanic white (2000), and percent veterans (2000). Economic distress, family distress, opioid prescribing (logged), and average opioid prescribing of neighboring counties (logged) are standardized to have a mean of 0 and standard deviation of 1 . The coefficients for those variables represent the change in the mortality rate for a 1 standard deviation increase in the predictor variable. 
Table 3. Results from Multivariate Random Effects Regression on County-Level Non-Hispanic White Drug Mortality Rates (201416), Stratified by Urban-Rural Continuum

\begin{tabular}{|c|c|c|c|c|c|c|c|}
\hline & $\begin{array}{l}\text { Large metro } \\
\text { Est.(S.E.) }\end{array}$ & $\begin{array}{l}\text { Small metr } \\
\text { Est.(S.E.) }\end{array}$ & & $\begin{array}{l}\text { Large nonmet, } \\
\text { adjacent to met } \\
\text { Est.(S.E.) }\end{array}$ & $\begin{array}{c}\text { Large nonmet, } \\
\text { not adjacent to } \\
\text { met } \\
\text { Est.(S.E.) }\end{array}$ & $\begin{array}{c}\text { Rural } \\
\text { Est.(S.E.) }\end{array}$ & \\
\hline Intercept & $27.47(1.23) * * *$ & $21.78(1.58)$ & $* * *$ & $22.10(1.19) * * *$ & $19.93(1.35) * * *$ & $18.83(1.69)$ & $* * *$ \\
\hline Economic distress, 2000 & $2.63(0.64) * * *$ & $1.38(1.22)$ & & $3.10(0.86) * * *$ & $5.02(1.05) * * *$ & $3.37(1.14)$ & $* *$ \\
\hline Family distress, 2000 & $2.60(0.62) * * *$ & $0.71(1.17)$ & & $1.92(0.81) *$ & $1.30(0.96)$ & $2.91(1.14)$ & $*$ \\
\hline \multicolumn{8}{|l|}{$\begin{array}{l}\text { Economic dependence, } 2004 \text { (ref }=\text { non- } \\
\text { specialized) }\end{array}$} \\
\hline Farming & $-2.28(2.66)$ & $0.87(2.60)$ & & $4.30(1.92) *$ & $-1.76(2.04)$ & $-1.60(1.91)$ & \\
\hline Mining & $0.70(3.76)$ & $16.46(4.05)$ & $* * *$ & $12.11(2.35) * * *$ & $6.39(2.18) * *$ & $2.33(3.16)$ & \\
\hline Manufacturing & $-3.63(0.95) * * *$ & $1.45(1.65)$ & & $-1.08(1.07)$ & $-1.51(1.51)$ & $0.30(2.17)$ & \\
\hline Public sector & $-3.15(1.28)^{*}$ & $-0.91(1.90)$ & & $-4.70(1.59) * *$ & $0.10(1.89)$ & $2.82(2.74)$ & \\
\hline Services & $2.43(1.09) *$ & $4.78(2.14)$ & $*$ & $5.02(2.14) *$ & $3.55(2.31)$ & $1.22(4.52)$ & \\
\hline Persistent population loss & $4.31(1.68) *$ & $4.74(2.19)$ & $*$ & $1.39(1.31)$ & $3.31(1.38) *$ & $1.56(1.81)$ & \\
\hline Opioid prescribing (logged) & $2.90(0.49) * * *$ & $2.15(0.65)$ & $* *$ & $1.77(0.53) * * *$ & $2.88(0.75) * * *$ & $1.57(0.62)$ & $*$ \\
\hline $\begin{array}{l}\text { Avg. opioid prescribing of neighboring } \\
\text { counties (logged) }\end{array}$ & $2.70(0.62) * * *$ & $2.13(0.76)$ & $* *$ & $3.57(0.59) * * *$ & $1.81(0.71) *$ & $1.62(0.92)$ & \\
\hline High fentanyl encounter state & $8.85(2.28) * * *$ & $5.88(2.79)$ & $*$ & $5.74(2.37) *$ & $3.55(2.72)$ & $3.29(2.85)$ & \\
\hline \multicolumn{8}{|l|}{ Error Variance } \\
\hline County-Level Variance & $93.86(4.90) * * *$ & $108.60(8.88)$ & $* * *$ & $131.17(6.80) * * *$ & $141.27(9.38) * * * 2$ & $232.20(14.26)$ & $* * *$ \\
\hline State-Level Variance & $28.54(9.61) * *$ & $28.19(10.01)$ & & $23.00(7.91)^{* *}$ & $17.40(8.12) *$ & $8.19(6.68)$ & \\
\hline County N & 805 & 351 & & 803 & 510 & 578 & \\
\hline State N & 44 & 45 & & 45 & 42 & 40 & \\
\hline
\end{tabular}

S.E. $=$ standard error; $* * * \mathrm{p}<.001 ; * * \mathrm{p}<.01 ; * \mathrm{p}<.05 ;$ two-tailed tests

All models control for county age composition (2000), percent non-Hispanic white (2000), and percent veterans (2000). Economic distress, family distress, opioid prescribing (logged), and average opioid prescribing of neighboring counties (logged) are standardized to have a mean of 0 and standard deviation of 1 . The coefficients for those variables represent the change in the mortality rate for a 1 standard deviation increase in the predictor variable. 


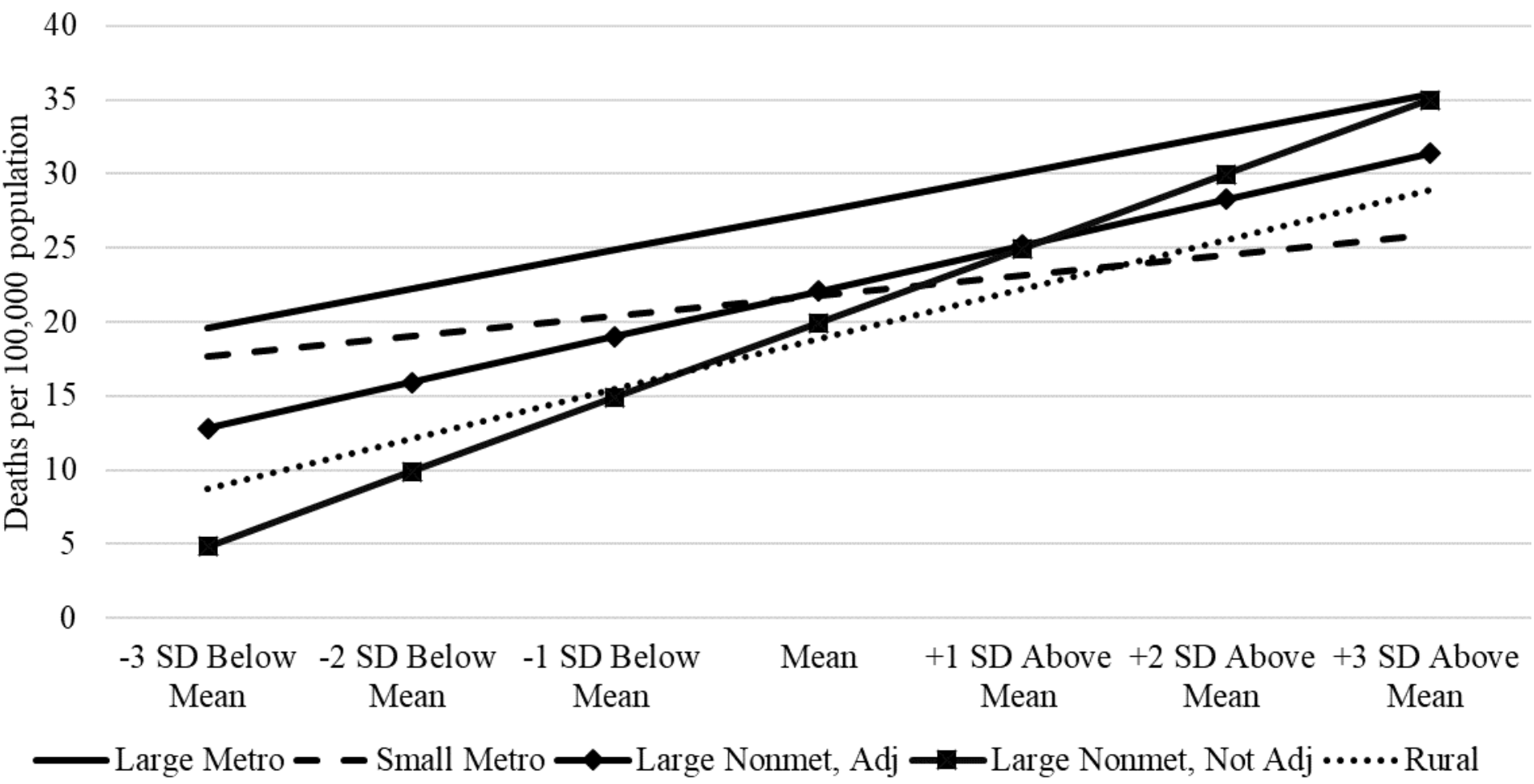

Figure 2. Model-Adjusted Relationship between Economic Distress and Non-Hispanic White Drug Mortality Rates by Urban-Rural Continuum

Note: Estimates hold all other variables constant 


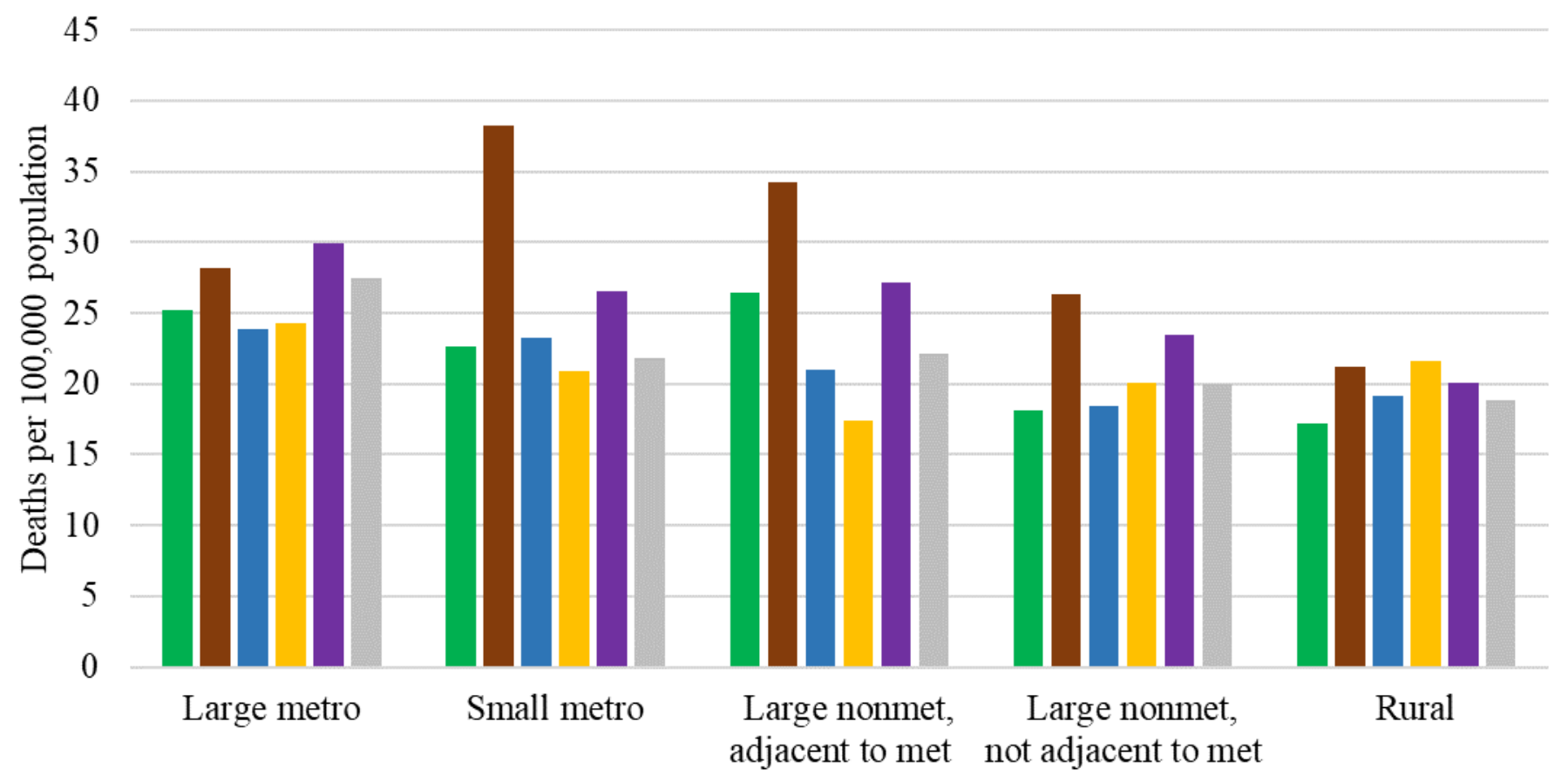

-Farming $\quad$ Mining $\square$ Manufacturing $\square$ Public sector $\square$ Services $\square$ Non-specialized

Figure 3. Model-Adjusted Relationship between Labor Market Type and Non-Hispanic White Drug Mortality Rates by Urban-Rural Continuum

Note: Estimates hold all other variables constant 
Table 4. Results from Multivariate Random Effects Regression on County-Level Non-Hispanic White Drug Mortality Rates (2014-16) among Nonmetro Counties Only, Stratified by Labor Market Dependence

\begin{tabular}{|c|c|c|c|c|c|c|}
\hline & $\begin{array}{c}\text { Farming } \\
\text { Est. (S.E.) }\end{array}$ & $\begin{array}{c}\text { Mining } \\
\text { Est. (S.E.) }\end{array}$ & $\begin{array}{r}\text { Manufacturing } \\
\text { Est. (S.E.) }\end{array}$ & $\begin{array}{c}\text { Services } \\
\text { Est. (S.E.) }\end{array}$ & $\begin{array}{c}\text { Public } \\
\text { Sector } \\
\text { (Gov.) } \\
\text { Est. (S.E.) }\end{array}$ & $\begin{array}{c}\text { Non- } \\
\text { Specialized } \\
\text { Est. (S.E.) }\end{array}$ \\
\hline Intercept & $\begin{array}{c}20.43 * * * \\
(1.63)\end{array}$ & $\begin{array}{c}23.45 * * * \\
(3.06)\end{array}$ & $\begin{array}{c}19.38 * * * \\
(1.05)\end{array}$ & $\begin{array}{c}26.27 * * * \\
(2.22)\end{array}$ & $\begin{array}{c}20.84 * * \\
(1.86)\end{array}$ & $\begin{array}{c}21.09 * * * \\
(1.25)\end{array}$ \\
\hline Economic distress, 2000 & $\begin{array}{l}-1.84 \\
(1.79)\end{array}$ & $\begin{array}{l}6.02 * \\
(2.80)\end{array}$ & $\begin{array}{c}1.63 \\
(1.15)\end{array}$ & $\begin{array}{c}7.94 * * * \\
(2.14)\end{array}$ & $\begin{array}{c}2.82 \\
(1.64)\end{array}$ & $\begin{array}{c}2.30 * * \\
(0.87)\end{array}$ \\
\hline Family distress, 2000 & $\begin{array}{l}3.01 * \\
(1.23)\end{array}$ & $\begin{array}{l}-2.70 \\
(3.15)\end{array}$ & $\begin{array}{c}3.70 * * * \\
(1.05)\end{array}$ & $\begin{array}{c}0.24 \\
(2.12)\end{array}$ & $\begin{array}{c}1.33 \\
(1.69)\end{array}$ & $\begin{array}{l}2.62 * * \\
(0.89)\end{array}$ \\
\hline Persistent population loss & $\begin{array}{l}-2.30 \\
(1.97)\end{array}$ & $\begin{array}{c}5.37 \\
(4.06)\end{array}$ & $\begin{array}{c}1.94 \\
(1.53)\end{array}$ & $\begin{array}{c}18.23 * * * \\
(5.13)\end{array}$ & $\begin{array}{c}2.25 \\
(4.50)\end{array}$ & $\begin{array}{c}1.18 \\
(1.31)\end{array}$ \\
\hline Opioid prescribing (logged) & $\begin{array}{c}0.71 \\
(0.66)\end{array}$ & $\begin{array}{l}4.57 * \\
(1.90)\end{array}$ & $\begin{array}{c}1.93 * * \\
(0.66)\end{array}$ & $\begin{array}{c}2.12 \\
(2.04)\end{array}$ & $\begin{array}{l}2.47 * \\
(1.19)\end{array}$ & $\begin{array}{c}2.43 * * * \\
(0.54)\end{array}$ \\
\hline Avg. opioid prescribing of neighboring counties (logged) & $\begin{array}{c}2.12 \\
(1.11)\end{array}$ & $\begin{array}{l}8.97 * * \\
(2.94)\end{array}$ & $\begin{array}{c}2.07 * * \\
(0.69)\end{array}$ & $\begin{array}{c}2.09 \\
(1.38)\end{array}$ & $\begin{array}{c}2.50 \\
(1.33)\end{array}$ & $\begin{array}{c}2.32 * * * \\
(0.70)\end{array}$ \\
\hline High fentanyl encounter state & $\begin{array}{r}2.77 \\
(8.14) \\
\end{array}$ & $\begin{array}{l}-7.66 \\
(7.02) \\
\end{array}$ & $\begin{array}{l}4.62 * \\
(2.19) \\
\end{array}$ & $\begin{array}{r}4.57 \\
(3.12) \\
\end{array}$ & $\begin{array}{c}0.63 \\
(4.50) \\
\end{array}$ & $\begin{array}{l}8.27 * \\
(3.11) \\
\end{array}$ \\
\hline \multicolumn{7}{|l|}{ Error Variance } \\
\hline County-Level Variance & $\begin{array}{c}187.4 * * * \\
(14.88)\end{array}$ & $\begin{array}{c}280.81 * * * \\
(44.33)\end{array}$ & $\begin{array}{c}139.46 * * * \\
(8.69)\end{array}$ & $\begin{array}{c}132.66 * * * \\
(20.23)\end{array}$ & $\begin{array}{c}214.43 * * * \\
(24.39)\end{array}$ & $\begin{array}{c}121.38 * * * \\
(7.56)\end{array}$ \\
\hline State-Level Variance & $\begin{array}{c}12.14 \\
(10.80)\end{array}$ & $\begin{array}{c}21.63 \\
(33.50)\end{array}$ & $\begin{array}{c}13.07 * \\
(6.68)\end{array}$ & $\begin{array}{c}0.00 \\
(0.00)\end{array}$ & $\begin{array}{l}33.17 * \\
(19.38)\end{array}$ & $\begin{array}{c}34.87 * * \\
(13.70)\end{array}$ \\
\hline $\mathrm{N}$ & 357 & 106 & 555 & 96 & 194 & 583 \\
\hline
\end{tabular}

S.E.=standard error;

$* * * \mathrm{p}<.001 ; * *_{\mathrm{p}}<.01 ; * \mathrm{p}<.05 ;$ two-tailed tests

All models control for county age composition (2000), percent non-Hispanic white (2000), and percent veterans (2000). Economic distress, family distress, opioid prescribing (logged), and average opioid prescribing of neighboring counties (logged) are standardized to have a mean of 0 and standard deviation of 1 . The coefficients for those variables represent the change in the mortality rate for a 1 standard deviation increase in the predictor variable. 


\section{APPENDIX A}

Table A1. ICD-10 codes identified as drug-related

\begin{tabular}{|l|l|}
\hline Category & ICD-10 code \\
\hline $\begin{array}{l}\text { Poisoning due to drugs (accidental, intentional, underdetermined } \\
\text { intent) }\end{array}$ & X40-X44, X60-64, Y10-Y14 \\
\hline Drug-induced diseases & D52.1, D59.0, D59.2, D61.1, D64.2, E06.4, E16.0, E23.1, \\
& E24.2, E27.3, E66.1, G21.1, G24.0, G25.1, G25.4, G25.6, \\
G44.4, G62.0, G72.0, I95.2, J70.2-J70.4, K85.3, L10.5, L27.0, \\
\hline Finding of drugs in the blood & R778.1-R78.5, M32.0, M80.4, M81.4, M83.5, M87.1, R50.2 \\
\hline Mental and behavioral disorders due to drugs & F11.0-F11.5, F11.7-F11.9, F12.0-F12.5, F12.7-F12.9, F13.0- \\
& F13.5, F13.7-F13.9, F14.0-F14.5, F14.7-F14.9, F15.0-F15.5, \\
& F15.7-F15.9, F16.0-F16.5, F16.7-F16.9, F18.0-F18.5, F18.7- \\
& F18.9, F19.0-F19.5, F19.7-F19.9 \\
\hline
\end{tabular}


Table A2. Variables Included in Regression Analysis with Summary Statistics, by Urban-Rural Continuum

\begin{tabular}{|c|c|c|c|c|c|}
\hline & $\begin{array}{c}\text { Large Metro } \\
\mathrm{N}=805\end{array}$ & $\begin{array}{c}\text { Small Metro } \\
\mathrm{N}=351\end{array}$ & $\begin{array}{c}\text { Large } \\
\text { Nonmet, } \\
\text { Adjacent to } \\
\text { Metro } \\
\mathrm{N}=803 \\
\end{array}$ & $\begin{array}{c}\text { Large } \\
\text { Nonmet, Not } \\
\text { Adjacent to } \\
\text { Metro } \\
\mathrm{N}=510 \\
\end{array}$ & $\begin{array}{c}\text { Rural } \\
\mathrm{N}=578\end{array}$ \\
\hline Variable & Mean/\% SD & Mean/\% SD & Mean $/ \%$ SD & Mean $/ \% \mathrm{SD}$ & Mean $/ \% \mathrm{SD}$ \\
\hline Non-Hispanic white age-adjusted drug mortality rate, $2000-02$ & $9.3(5.8)$ & $7.9(5.2)$ & $8.0(6.0)$ & $8.2(7.6)$ & $6.0(8.6)$ \\
\hline Non-Hispanic white age-adjusted drug mortality rate, 2014-16 & $26.7(13.1)$ & $23.8(13.8)$ & $24.2(14.6)$ & $22.6(15.3)$ & $18.5(17.3)$ \\
\hline Change in drug mortality rate, $200-02$ to $2014-16$ & $17.3(11.5)$ & $15.9(13.0)$ & $16.3(13.9)$ & $14.5(13.3)$ & $12.5(17.0)$ \\
\hline Economic Distress Index Measures, 2000 & $-0.6(0.9)$ & $-0.2(0.8)$ & $0.2(0.8)$ & $0.2(1.0)$ & $0.4(1.0)$ \\
\hline Percent poverty & $11.0(5.3)$ & $13.5(5.2)$ & $14.9(6.1)$ & $15.5(6.5)$ & $16.0(6.6)$ \\
\hline Ratio of state-to-county median household income & $99.2(19.9)$ & $112.4(18.1)$ & $122.5(18.9)$ & $125.2(20.8)$ & $131.2(21.6)$ \\
\hline Percent households receiving public assistance income & $2.9(1.5)$ & $3.2(1.4)$ & $3.6(1.6)$ & $3.8(1.9)$ & $3.5(2.2)$ \\
\hline Percent $\mathrm{w}<4$-year college degree & $78.9(9.7)$ & $81.7(8.1)$ & $86.1(5.5)$ & $84.4(6.5)$ & $86.5(4.8)$ \\
\hline Percent not working & $38.5(6.5)$ & $41.0(6.9)$ & $44.0(6.7)$ & $43.8(7.9)$ & $45.3(7.4)$ \\
\hline Percent with a work disability & $11.7(2.8)$ & $11.7(3.2)$ & $12.9(3.1)$ & $12.4(3.4)$ & $12.4(3.8)$ \\
\hline Family Distress Index Measures, 2000 & $0.1(0.9)$ & $0.1(0.9)$ & $0.2(0.9)$ & $0.0(0.9)$ & $-0.5(1.1)$ \\
\hline Percent single-parent families & $11.7(1.9)$ & $11.6(2.2)$ & $11.6(2.0)$ & $11.3(2.2)$ & $10.2(2.6)$ \\
\hline Percent divorced/separated & $26.2(7.4)$ & $27.0(6.0)$ & $27.5(6.5)$ & $26.5(6.8)$ & $23.1(7.5)$ \\
\hline \multicolumn{6}{|l|}{ ERS Labor Market Dependence, 2004 (\%) } \\
\hline Farming & 2.0 & 7.7 & 6.4 & 10.8 & 43.4 \\
\hline Mining & 1.0 & 2.3 & 3.7 & 8.8 & 5.4 \\
\hline Manufacturing & 30.7 & 29.1 & 43.1 & 24.9 & 14.2 \\
\hline Public (government) & 12.2 & 19.7 & 10.8 & 12.5 & 7.4 \\
\hline Services & 23.6 & 13.1 & 4.9 & 8.4 & 2.4 \\
\hline Non-specialized (reference) & 31.2 & 28.2 & 31.1 & 34.5 & 27.2 \\
\hline Persistent population loss (1980 to 2000) (\%) & 5.5 & 9.7 & 13.9 & 28.4 & 41.0 \\
\hline Opioid prescriptions per 100 residents, 2009-2011 & $84.8(40.8)$ & $90.4(50.0)$ & $94.0(48.7)$ & $100.3(57.6)$ & $62.2(46.7)$ \\
\hline Average opioid prescriptions among neighboring counties, 2009-11 & $73.1(22.7)$ & $72.6(26.0)$ & $73.7(25.5)$ & $71.2(30.4)$ & $71.8(30.9)$ \\
\hline
\end{tabular}


County in 'high fentanyl law enforcement encounter' state (\%)

Percent Non-Hispanic white, 2000

Percent veterans, 2000

Percent age $65+, 2000$

County N=3,047; State $\mathrm{N}=49$

$\mathrm{SD}=$ standard deviation
12.2

$\begin{array}{lr} & 15.4 \\ (17.9) & 82.5 \\ (2.7) & 14.1 \\ (3.4) & 13.6\end{array}$

15.4

15.9

(15.2) 81.2

(2.8) 13.9

(3.7) 15.0
11.6

(19.0) 82.7

(2.7) 13.7

(2.9) 15.5
11.8 (18.5) $87.1 \quad$ (16.9) (2.9) $14.3 \quad$ (2.9) (3.7) $18.2 \quad$ (4.2) 


\section{APPENDIX B}

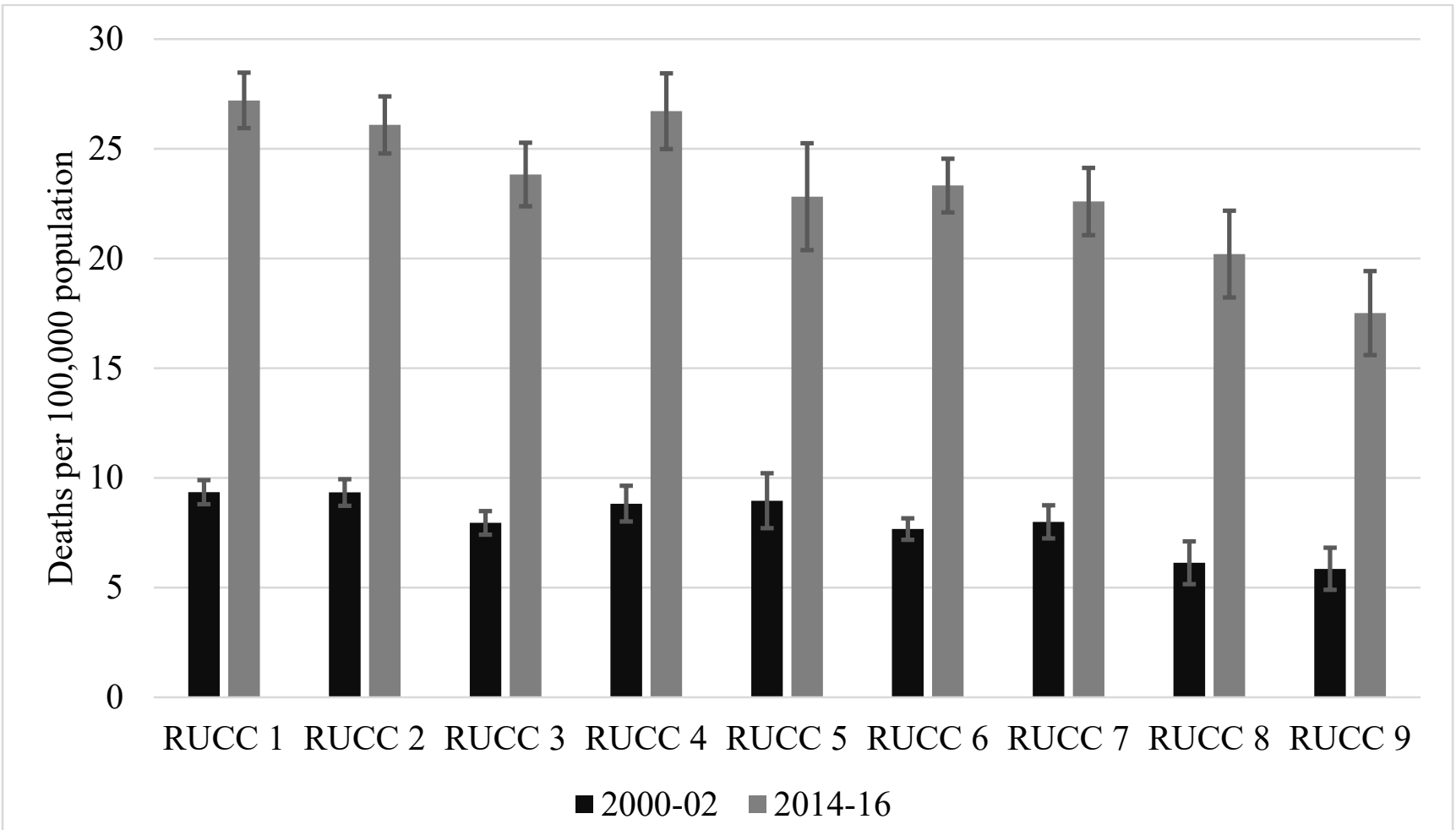

Figure B1. Average County Non-Hispanic White Drug Mortality Rates in 2000-02 and 2014-16, by the 9-Category Rural-Urban Continuum Code

Note: error bars represent $95 \%$ confidence intervals 


\section{Appendix C: Models Assessing Change in Drug Mortality Rates, 2000-02 to 2014-16}

Table C1. Results from Multivariate Random Effects Regression on Change (Logged) in County-Level Non-Hispanic White Drug Mortality Rates, 2000-02 to 2014-16

\begin{tabular}{|c|c|c|c|c|c|c|c|c|c|c|c|c|}
\hline & \multicolumn{3}{|c|}{ Model 1} & \multicolumn{3}{|c|}{ Model 2} & \multicolumn{3}{|c|}{ Model 3} & \multicolumn{3}{|c|}{ Model 4} \\
\hline & Estimate & (S.E.) & & Estimate & (S.E.) & & Estimate & (S.E.) & & Estimate & (S.E.) & \\
\hline Intercept & 4.77 & $(0.01)$ & $* * *$ & 4.78 & $(0.01)$ & $* * *$ & 4.76 & $(0.01)$ & $* * *$ & 4.76 & $(0.01)$ & $* * *$ \\
\hline $\begin{array}{l}\text { Non-Hispanic white drug } \\
\text { mortality rate, } 2000-02\end{array}$ & -2.66 & $(0.20)$ & $* * *$ & -3.55 & $(0.21)$ & $* * *$ & -3.79 & $(0.20)$ & $* * *$ & -3.97 & $(0.21)$ & $* * *$ \\
\hline \multicolumn{13}{|c|}{ Urban-Rural Continuum (ref=Large metro) } \\
\hline Small metro & -1.20 & $(0.67)$ & & -2.30 & $(0.66)$ & $* * *$ & -1.86 & $(0.65)$ & $* *$ & -2.10 & $(0.65)$ & $* *$ \\
\hline $\begin{array}{l}\text { Large nonmet, adjacent to } \\
\text { met } \\
\text { Large nonmet, not adjacent }\end{array}$ & -1.43 & $(0.55)$ & $* *$ & -3.07 & $(0.58)$ & $* * *$ & -2.78 & $(0.57)$ & $* * *$ & -2.85 & $(0.56)$ & $* * *$ \\
\hline to met & -1.64 & $(0.65)$ & $*$ & -4.04 & $(0.67)$ & $* * *$ & -3.88 & $(0.67)$ & $* * *$ & -3.83 & $(0.66)$ & $* * *$ \\
\hline Rural & -4.02 & $(0.70)$ & $* * *$ & -5.86 & $(0.76)$ & $* * *$ & -4.95 & $(0.75)$ & $* * *$ & -4.73 & $(0.75)$ & $* * *$ \\
\hline Economic distress, 2000 & & & & 2.24 & $(0.31)$ & $* * *$ & 1.55 & $(0.33)$ & $* * *$ & 1.65 & $(0.39)$ & $* * *$ \\
\hline Family distress, 2000 & & & & 2.38 & $(0.31)$ & $* * *$ & 1.85 & $(0.31)$ & $* * *$ & 1.90 & $(0.32)$ & $* * *$ \\
\hline \multicolumn{13}{|c|}{ Economic dependence, 2004 (ref=non-specialized) } \\
\hline Farming & & & & -0.43 & $(0.72)$ & & -0.10 & $(0.71)$ & & -0.34 & $(0.70)$ & \\
\hline Mining & & & & 5.59 & $(1.00)$ & $* * *$ & 5.48 & $(0.98)$ & $* * *$ & 5.00 & $(0.99)$ & $* * *$ \\
\hline Manufacturing & & & & -1.25 & $(0.50)$ & $*$ & -1.32 & $(0.49)$ & $* *$ & -1.16 & $(0.48)$ & $*$ \\
\hline Public sector & & & & -1.54 & $(0.65)$ & $*$ & -1.48 & $(0.64)$ & $* *$ & -1.41 & $(0.64)$ & $*$ \\
\hline Services & & & & 2.44 & $(0.71)$ & $* * *$ & 2.09 & $(0.70)$ & $* *$ & 2.09 & $(0.69)$ & $* *$ \\
\hline Persistent population loss & & & & 1.63 & $(0.56)$ & $* *$ & 1.53 & $(0.55)$ & $* *$ & 1.53 & $(0.55)$ & $* *$ \\
\hline Opioid prescribing (logged) & & & & & & & 1.46 & $(0.21)$ & $* * *$ & 1.77 & $(0.32)$ & $* * *$ \\
\hline $\begin{array}{l}\text { Avg. opioid prescribing of } \\
\text { neighboring counties }\end{array}$ & & & & & & & & & & & & \\
\hline (logged) & & & & & & & 1.92 & $(0.27)$ & $* * *$ & 1.83 & $(0.26)$ & $* * *$ \\
\hline $\begin{array}{l}\text { High fentanyl encounter } \\
\text { state }\end{array}$ & & & & & & & 5.72 & $(1.43)$ & $* * *$ & 5.65 & $(1.11)$ & $* * *$ \\
\hline
\end{tabular}

Error Variance 


\begin{tabular}{|c|c|c|c|c|c|c|c|c|c|c|c|c|}
\hline County-Level Variance & 0.0103 & 0.0003 & $* * *$ & 0.0095 & 0.0002 & $* * *$ & 0.0090 & 0.0002 & $* * *$ & 0.0091 & 0.0002 & $* * *$ \\
\hline State-Level Variance & 0.0030 & 0.0007 & $* * *$ & 0.0022 & 0.0005 & $* * *$ & 0.0010 & 0.0003 & $* * *$ & 0.0012 & 0.0003 & $* * *$ \\
\hline Economic Distress & & & & & & & & & & 0.00 & $(0.00)$ & $*$ \\
\hline Opioid Prescribing & & & & & & & & & & 0.00 & $(0.00)$ & $*$ \\
\hline \multicolumn{13}{|l|}{ Model Fit } \\
\hline AIC & -5081.3 & & & -5259.2 & & & -5340.7 & & & -5368.9 & & \\
\hline $\mathrm{BIC}$ & -5077.6 & & & -5255.4 & & & -5336.9 & & & -5355.7 & & \\
\hline
\end{tabular}

County $\mathrm{N}=3,047 ;$ State $\mathrm{N}=49$

$\mathrm{SE}=$ standard error; $* * * \mathrm{p}<.001 ; * * \mathrm{p}<.01 ; * \mathrm{p}<.05 ;$ two-tailed tests

Multilevel models; All models control for county age composition (2000), percent non-Hispanic white (2000), and percent veterans

(2000). The dependent variable (absolute change in the drug mortality rate) is logged; coefficients represent the percentage change in the absolute rate between 2000-02 and 2014-16. Non-Hispanic White drug mortality rate for 2000-02, economic distress, family distress, opioid prescribing (logged), and average opioid prescribing of neighboring counties (logged) are standardized to have a mean of 0 and standard deviation of 1 . The coefficients for those variables represent the percentage change in the mortality rate for a 1 standard deviation increase in the predictor variable. 
Table C3. Results from Multivariate Random Effects Regression on Change (Logged) in County-Level Non-Hispanic White Drug Mortality Rates (2000-02 to 2014-16) among Nonmetro Counties Only, Stratified by Labor Market Dependence

\begin{tabular}{|c|c|c|c|c|c|c|}
\hline & Farming & Mining & Manufacturing & Services & $\begin{array}{l}\text { Public } \\
\text { Sector }\end{array}$ & $\begin{array}{c}\text { Non- } \\
\text { Specialized }\end{array}$ \\
\hline & Est. (S.E.) & Est. (S.E.) & Est. (S.E.) & Est. (S.E.) & Est. (S.E.) & Est. (S.E.) \\
\hline \multirow[t]{2}{*}{ Intercept } & $4.72 * * *$ & $4.75 * * *$ & $4.71 * * *$ & $4.76^{* * *}$ & $4.72 * * *$ & $4.73 * * *$ \\
\hline & $(0.14)$ & $(0.02)$ & $(0.01)$ & $(0.02)$ & $(0.01)$ & $(0.01)$ \\
\hline \multirow[t]{2}{*}{ Non-Hispanic white drug mortality rate, $2000-02$} & -5.65 & $-2.34 *$ & $-4.28 * * *$ & $-3.10 * *$ & $-2.66^{* *}$ & $-4.26 * * *$ \\
\hline & $(0.53)$ & $(0.95)$ & $(0.54)$ & $(1.12)$ & $(0.89)$ & $(0.47)$ \\
\hline \multirow[t]{2}{*}{ Economic distress, 2000} & -1.90 & 3.07 & .87 & $5.79 * *$ & 1.22 & 1.02 \\
\hline & $(1.54)$ & $(2.12)$ & $(0.95)$ & $(1.68)$ & $(1.25)$ & $(0.75)$ \\
\hline \multirow[t]{2}{*}{ Family distress, 2000} & $2.99 * *$ & -1.26 & $2.51 * *$ & -0.66 & 1.29 & $2.45^{* *}$ \\
\hline & $(1.06)$ & $(2.34)$ & $(0.89)$ & $(1.70)$ & $(1.26)$ & $(0.74)$ \\
\hline \multirow[t]{2}{*}{ Persistent population loss } & -2.03 & 1.79 & 1.86 & $14.28 * * *$ & 2.94 & .83 \\
\hline & (1.69) & $(3.08)$ & $(0.13)$ & $(4.02)$ & $(3.38)$ & (1.09) \\
\hline \multirow[t]{2}{*}{ Opioid prescribing (logged) } & .518 & 2.55 & $1.43 * *$ & 1.17 & 1.20 & $1.85 * * *$ \\
\hline & $(0.56)$ & $(1.46)$ & $(0.55)$ & $(1.64)$ & $(0.92)$ & $(0.46)$ \\
\hline \multirow[t]{2}{*}{ Avg. opioid prescribing of neighboring counties (logged) } & 1.71 & $6.53 * *$ & $1.86^{* *}$ & 1.45 & 1.79 & $2.04 * * *$ \\
\hline & $(0.94)$ & $(2.20)$ & $(0.57)$ & $(1.08)$ & $(1.01)$ & $(0.59)$ \\
\hline \multirow[t]{2}{*}{ High fentanyl encounter state } & 2.53 & -3.74 & $3.80 *$ & 4.27 & .94 & $7.17 * *$ \\
\hline & $(7.01)$ & $(5.11)$ & $(1.72)$ & $(2.45)$ & $(3.35)$ & $(2.38)$ \\
\hline \multicolumn{7}{|l|}{ Error Variance } \\
\hline \multirow[t]{2}{*}{ County-Level Variance } & $.013 * * *$ & $.016^{* * *}$ & $.010 * * *$ & $.008 * * *$ & $.012 * * *$ & $.008 * * *$ \\
\hline & $(0.001)$ & $(0.003)$ & $(0.001)$ & $(0.001)$ & $(0.001)$ & $(0.001)$ \\
\hline \multirow[t]{2}{*}{ State-Level Variance } & .001 & .001 & $.001 *$ & 0.00 & $.002 *$ & $.002 * *$ \\
\hline & $(0.001)$ & $(0.002)$ & $(0.000)$ & $(0.000)$ & $(0.001)$ & $(0.001)$ \\
\hline $\mathrm{N}$ & 357 & 106 & 555 & 96 & 194 & 583 \\
\hline
\end{tabular}

$\mathrm{SE}=$ standard error; $* * * \mathrm{p}<.001 ; * * \mathrm{p}<.01 ; * \mathrm{p}<.05 ;$ two-tailed tests

Multilevel models; All models control for county age composition (2000), percent non-Hispanic white (2000), and percent veterans (2000). The dependent variable (absolute change in the drug mortality rate) is logged; coefficients represent the percentage change in the absolute rate between 2000-02 and 2014-16. Non-Hispanic white drug mortality rate for 2000-02, economic distress, family distress, opioid prescribing (logged), and average opioid prescribing of neighboring counties (logged) are standardized to have a mean of 0 and standard deviation of 1 . The coefficients for those variables represent the percentage change in the mortality rate for a 1 standard deviation increase in the predictor variable. 


\section{APPENDIX D: Spatial Analysis}

Results from the spatial models are presented in Tables D1-D8. All variables from the main multilevel models presented in the main text, with the exception of fentanyl exposure (a state-level variable), are included in these models. Fentanyl exposure is excluded because, to my knowledge, simultaneous random intercept and spatial models are not possible. All models control for county age composition (2000), percent non-Hispanic white (2000), and percent veterans (2000).

Model 1 includes a spatial lag for the dependent variable ( $\mathrm{NH}$ white drug mortality rate, 2014-16), specified as:

$$
\mathrm{y}_{\text {mort }}=\beta_{0}+\beta_{\mathrm{k}} \mathrm{Xk}_{\mathrm{k}}+\beta_{2} \mathrm{Wy} \mathrm{y}_{\mathrm{mort}}+\varepsilon
$$

where $y_{\text {mort }}$ is the predicted county drug mortality rate, $\beta_{0}$ is the intercept, $\beta_{\mathrm{kXk}}$ is a vector of county-level independent variables, $\beta_{2} \mathrm{Wymort}$ is the spillover effect of the drug mortality rate from neighboring counties (W represents the spatial weighting matrix), and $\varepsilon$ is the residual.

Model 2 introduces spatial lags for two of the independent variables (economic distress and opioid prescribing), specified as:

$$
\mathrm{y}_{\text {mort }}=\beta_{0}+\beta_{\mathrm{k}} \mathrm{Xk}_{\mathrm{k}}+\beta_{2} \mathrm{Wy}_{\mathrm{mort}}+\beta_{3} \mathrm{WX}_{\text {econ }}+\beta_{4} \mathrm{~W} \mathrm{x}_{\mathrm{rx}}+\varepsilon,
$$

where $y_{\text {mort }}$ is the predicted county drug mortality rate, $\beta_{0}$ is the intercept, $\beta_{\mathrm{k}} \mathrm{x}_{\mathrm{k}}$ is a vector of county-level independent variables, $\beta_{2} \mathrm{Wy}$ mort is the spillover effect of the drug mortality rate from neighboring counties, $\beta_{3} \mathrm{Wx}_{\mathrm{x} \text { econ }}$ is the spillover effect of economic distress from neighboring counties, $\beta_{4} \mathrm{Wx}_{\mathrm{rx}}$ is the spillover effect of opioid prescribing from neighboring counties, and $\varepsilon$ is the residual.

Model 3 introduces a spatially autoregressive error term (errors from neighboring counties), specified as:

$$
\mathrm{y}_{\text {mort }}=\beta_{0}+\beta_{\mathrm{k}} \mathrm{X}_{\mathrm{k}}+\beta_{2} \mathrm{Wy}_{\mathrm{mort}}+\beta_{3} \mathrm{Wx}_{\mathrm{xecon}}+\beta_{4} \mathrm{Wx}_{\mathrm{rx}}+(\mathrm{I}-\rho \mathrm{W})^{-1} \varepsilon,
$$

where the betas remain the same as above, and $(\mathrm{I}-\rho \mathrm{W})^{-1} \varepsilon$ represents the spatial lag of the error

Table D1 presents the results from the spatial regression models predicting non-Hispanic white drug mortality rates for 2014-16. Here I discuss the results of the fully-specified model (Model 3). Findings are very similar to the fully-specified model from the main analysis presented in the main text (random effects model). Net of controls, drug mortality rates are precipitously lower as we move from the most urban to the most rural counties. Economic distress, family distress, persistent population loss, opioid prescribing, and labor market dependence on the service or mining sectors are associated with significantly higher drug mortality rates. Dependence on manufacturing is associated with significantly lower mortality rates. The significant positive spatial lag for the dependent variable (Wymort) indicates that there is positive spillover effects across counties; counties with higher drug mortality rates contribute to higher drug mortality rates among their neighbors. The positive spatial lag for prescribing ( $\left.\mathrm{Wx}_{\mathrm{rx}}\right)$ likewise indicates that there are prescribing spillover effects across counties; not only are within-county prescribing rates associated with higher mortality rates within that county, but counties surrounded by others with high prescribing rates also experience an indirect effect of 
higher mortality rates from the spillover from their neighboring counties. This implies opioid diversion across counties. Conversely, the negative spatial lag for economic distress (Wxecon) suggests that, net of one's own level of economic distress, a county surrounded by more economically distressed counties has lower drug mortality rates. The direct effect of economic distress is still positive and significant; counties with more economic distress have higher drug mortality rates. The spatial error $\left((\mathrm{I}-\rho \mathrm{W})^{-1} \varepsilon\right.$ is significant, but small $\left.(0.25)\right)$, suggesting that drug mortality rates are positively affected, though only slightly so, by the error from neighboring counties, implying potential omitted variables.

Margins (direct, indirect, and total effects) for all three models are presented in Tables D2-D4. The direct effects are the effects of the predictor variable within the county, ignoring spillover effects. For example, in Table D4 (margins corresponding to Model 3 in table D1), the direct effect of a one standard deviation increase in opioid prescribing within the average county is an increase of 2.38 deaths per 100,000 population. The indirect effect is the spillover effect from all the spatial lags included in the model (in this case, the lag of the DV, economic distress, and opioid prescribing). An increase in opioid prescribing increases the drug mortality rate, and that increase spills over to further increase drug mortality rates in neighboring counties. The result for opioid prescribing spillover is an additional average increase of 4.92 deaths per 100,000 population.

Results from the spatial regression models that include state fixed effects are presented in Table D5. Model margins (direct, indirect, and total effects) are shown in Tables D6-D8. Although the magnitude of the coefficients for the independent variables differ slightly, the overall conclusions remain the same as with the model without state fixed effects. The effects of the spatial lags for the dependent variable, economic distress, and opioid prescribing also remain similar as those in the models without state fixed effects. However, with the addition of state fixed effects, the spatial error term is no longer significant (Table D5, Model 3), suggesting that the omitted variable(s) (spatial lag of the error, $\left.(\mathrm{I}-\mathrm{pW})^{-1} \varepsilon\right)$ implied in the models without state fixed effects (Table D1, Model 3) may be at the state level. Accordingly, state-level effects are important to account for when attempting to predict spatial variation in drug mortality rates.

Ultimately, the results from these spatial models are nearly identical to those from the multilevel models (MLMs) presented in the main text. The main exception is that labor market dependence on the public sector (government employment) was associated with significantly lower drug mortality rates in the MLMs but was not significant in the spatial models. However, even in the MLMs, the coefficient was small (a reduction of 1.70 deaths per 100,000 population in public sector vs. non-specialized counties). 
Table D1. Results from Spatial Regression Models Predicting Non-Hispanic White Drug Mortality Rates, 2014-16

\begin{tabular}{|c|c|c|c|c|c|c|c|c|c|}
\hline & \multicolumn{3}{|c|}{ Model 1} & \multicolumn{3}{|c|}{ Model 2} & \multicolumn{3}{|c|}{ Model 3} \\
\hline & Est. & S.E. & & Est. & S.E. & & Est. & S.E. & \\
\hline Intercept & 18.55 & $(0.98)$ & $* * *$ & 19.31 & $(1.06)$ & $* * *$ & 19.48 & $(1.05)$ & $* * *$ \\
\hline \multicolumn{10}{|l|}{ Urban-Rural Continuum (ref=Large metro) } \\
\hline Small metro & -3.10 & $(0.72)$ & $* * *$ & -2.42 & $(0.71)$ & $* *$ & -2.05 & $(0.72)$ & $* *$ \\
\hline Large nonmet, adjacent to met & -4.59 & $(0.65)$ & $* * *$ & -4.08 & $(0.65)$ & $* * *$ & -3.73 & $(0.65)$ & $* * *$ \\
\hline Large nonmet, not adjacent to met & -5.95 & $(0.78)$ & $* * *$ & -4.85 & $(0.78)$ & $* * *$ & -4.29 & $(0.82)$ & $* * *$ \\
\hline Rural & -6.57 & $(1.02)$ & $* * *$ & -6.20 & $(1.02)$ & $* * *$ & -5.69 & $(1.03)$ & $* * *$ \\
\hline Economic distress, 2000 & 3.45 & $(0.43)$ & $* * *$ & 4.19 & $(0.54)$ & $* * *$ & 3.95 & $(0.53)$ & $* * *$ \\
\hline Family distress, 2000 & 2.57 & $(0.44)$ & $* * *$ & 2.29 & $(0.44)$ & $* * *$ & 2.58 & $(0.46)$ & $* * *$ \\
\hline \multicolumn{10}{|c|}{ Economic dependence, 2004 (ref=non-specialized) } \\
\hline Services & 4.24 & $(0.81)$ & $* * *$ & 4.17 & $(0.80)$ & $* * *$ & 3.92 & $(0.80)$ & $* * *$ \\
\hline Public sector & -0.77 & $(0.80)$ & & -0.54 & $(0.81)$ & & -0.52 & $(0.81)$ & \\
\hline Manufacturing & -0.80 & $(0.52)$ & & -1.29 & $(0.52)$ & * & -1.20 & $(0.52)$ & $*$ \\
\hline Mining & 7.11 & $(1.69)$ & $* * *$ & 7.52 & $(1.67)$ & $* * *$ & 6.45 & $(1.70)$ & $* * *$ \\
\hline Farming & -0.28 & $(0.92)$ & & -0.49 & $(0.92)$ & & -0.32 & $(0.96)$ & \\
\hline Persistent population loss & 1.80 & $(0.76)$ & * & 2.07 & $(0.75)$ & $* *$ & 1.98 & $(0.77)$ & $*$ \\
\hline Opioid prescribing (logged) & 2.22 & $(0.30)$ & $* * *$ & 2.21 & $(0.31)$ & $* * *$ & 2.18 & $(0.31)$ & $* * *$ \\
\hline Spatial lag of drug mortality rate ( $\left.\mathrm{Wy}_{\text {mort }}\right)$ & 0.39 & $(0.03)$ & $* * *$ & 0.33 & $(0.04)$ & $* * *$ & 0.31 & $(0.04)$ & $* * *$ \\
\hline Spatial lag of economic distress $\left(\mathrm{Wx}_{\mathrm{econ}}\right)$ & & & & -2.79 & $(0.59)$ & $* * *$ & -2.61 & $(0.60)$ & $* * *$ \\
\hline Spatial lag of opioid prescribing $\left(\mathrm{Wx}_{\mathrm{rx}}\right)$ & & & & 3.51 & $(0.58)$ & $* * *$ & 3.50 & $(0.61)$ & $* * *$ \\
\hline Spatial error $(\mathrm{I}-p \mathrm{~W})^{-1} \varepsilon$ & & & & & & & 0.25 & $(0.05)$ & $* * *$ \\
\hline Pseudo $\mathrm{R}^{2}$ & 0.2673 & & & 0.2908 & & & 0.2864 & & \\
\hline
\end{tabular}

$\mathrm{SE}=$ standard error; $* * * \mathrm{p}<.001 ; * * \mathrm{p}<.01 ; * \mathrm{p}<.05 ;$ two-tailed tests

All models control for county age composition (2000), percent non-Hispanic white (2000), and percent veterans (2000). Economic distress, family distress, and opioid prescribing (logged) are standardized to have a mean of 0 and standard deviation of 1.

Model 1: includes spatial lag of the dependent variable

Model 2: includes spatial lag of the dependent variable and spatial lags for economic distress and opioid prescribing

Model 3: includes spatial lag of the dependent variable, spatial lags for economic distress and opioid prescribing, and a spatially autoregressive error 
Table D2. Margins from Spatial Lag of DV Model (Model 1 in Table D1)

\begin{tabular}{|c|c|c|c|c|c|c|c|c|c|}
\hline \multirow[b]{2}{*}{ Urban-Rural Continuum (ref=Large metro) } & \multicolumn{3}{|c|}{ Direct Effect } & \multicolumn{2}{|c|}{ Indirect Effect } & & \multicolumn{2}{|c|}{ Total Effect } & \\
\hline & & & & & & & & & \\
\hline Small metro & -3.17 & $(0.73)$ & $* * *$ & -1.57 & $(0.38)$ & $* * *$ & -4.73 & $(1.08)$ & $* * *$ \\
\hline Large nonmet, adjacent to met & -4.70 & $(0.66)$ & $* * *$ & -2.32 & $(0.40)$ & $* * *$ & -7.02 & $(0.98)$ & $* * *$ \\
\hline Large nonmet, not adjacent to met & -6.09 & $(0.79)$ & $* * *$ & -3.01 & $(0.47)$ & $* * *$ & -9.11 & $(1.15)$ & $* * *$ \\
\hline Rural & -6.72 & $(1.03)$ & $* * *$ & -3.32 & $(0.59)$ & $* * *$ & -10.04 & $(1.51)$ & $* * *$ \\
\hline Economic distress, 2000 & 3.53 & $(0.43)$ & $* * *$ & 1.75 & $(0.27)$ & $* * *$ & 5.28 & $(0.63)$ & $* * *$ \\
\hline Family distress, 2000 & 2.63 & $(0.45)$ & $* * *$ & 1.30 & $(0.27)$ & $* * *$ & 3.92 & $(0.68)$ & $* * *$ \\
\hline $\begin{array}{l}\text { Economic dependence, } 2004(\mathrm{ref}=\mathrm{nc} \\
\text { specialized })\end{array}$ & & & & & & & & & \\
\hline Services & 4.34 & $(0.82)$ & $* * *$ & 2.15 & $(0.48)$ & $* * *$ & 6.49 & $(1.24)$ & $* * *$ \\
\hline Public sector & -0.79 & $(0.82)$ & & -0.39 & $(0.41)$ & & -1.18 & $(1.22)$ & \\
\hline Manufacturing & -0.81 & $(0.53)$ & & -0.40 & $(0.27)$ & & -1.22 & $(0.80)$ & \\
\hline Mining & 7.27 & $(1.72)$ & $* * *$ & 3.59 & $(0.92)$ & $* * *$ & 10.87 & $(2.56)$ & $* * *$ \\
\hline Farming & -0.29 & $(0.95)$ & & -0.14 & $(0.47)$ & & -0.43 & $(1.41)$ & \\
\hline Persistent population loss & 1.84 & $(0.78)$ & * & 0.91 & $(0.40)$ & * & 2.75 & $(1.17)$ & * \\
\hline Opioid prescribing (logged) & 2.27 & $(0.31)$ & $* * *$ & 1.12 & $(0.19)$ & $* * *$ & 3.40 & $(0.46)$ & $* * *$ \\
\hline
\end{tabular}

$\mathrm{SE}=$ standard error; $* * * \mathrm{p}<.001 ; * * \mathrm{p}<.01 ;{ }^{*} \mathrm{p}<.05 ;$ two-tailed tests

All models control for county age composition (2000), percent non-Hispanic white (2000), and percent veterans (2000). Economic distress, family distress, and opioid prescribing (logged) are standardized to have a mean of 0 and standard deviation of 1 .

Direct effect: effect of the change within the county, ignoring spillover effects

Indirect effect: spillover effect

Total effect: sum of the direct and indirect effects 
Table D3. Margins from Spatial Lag of DV \& Spatial Lag of IVs Model (Model 2 in Table D1)

\begin{tabular}{|c|c|c|c|c|c|c|c|c|c|}
\hline & \multicolumn{3}{|c|}{ Direct Effect } & \multicolumn{3}{|c|}{ Indirect Effect } & \multicolumn{3}{|c|}{ Total Effect } \\
\hline \multirow{2}{*}{\multicolumn{10}{|c|}{$\begin{array}{l}\text { Urban-Rural Continuum (ref=Large } \\
\text { metro) }\end{array}$}} \\
\hline & & & & & & & & & \\
\hline Small metro & -2.46 & $(0.72)$ & $* *$ & -0.96 & $(0.31)$ & $* *$ & -3.42 & $(1.00)$ & $* *$ \\
\hline Large nonmet, adjacent to met & -4.15 & $(0.65)$ & $* * *$ & -1.62 & $(0.35)$ & $* * *$ & -5.78 & $(0.92)$ & $* * *$ \\
\hline Large nonmet, not adjacent to met & -4.93 & $(0.79)$ & $* * *$ & -1.93 & $(0.40)$ & $* * *$ & -6.86 & $(1.09)$ & $* * *$ \\
\hline Rural & -6.30 & $(1.03)$ & $* * *$ & -2.46 & $(0.49)$ & $* * *$ & -8.77 & $(1.40)$ & $* * *$ \\
\hline Economic distress, 2000 & 4.12 & $(0.53)$ & $* * *$ & -1.68 & $(0.61)$ & $* *$ & 2.44 & $(0.66)$ & $* * *$ \\
\hline Family distress, 2000 & 2.33 & $(0.45)$ & $* * *$ & 0.91 & $(0.23)$ & $* * *$ & 3.24 & $(0.64)$ & $* * *$ \\
\hline \multicolumn{10}{|l|}{$\begin{array}{l}\text { Economic dependence, } 2004 \text { (ref=non- } \\
\text { specialized) }\end{array}$} \\
\hline Services & 4.24 & $(0.81)$ & $* * *$ & 1.66 & $(0.41)$ & $* * *$ & 5.89 & $(1.15)$ & $* * *$ \\
\hline Public sector & -0.55 & $(0.82)$ & & -0.22 & $(0.32)$ & & -0.77 & $(1.14)$ & \\
\hline Manufacturing & -1.31 & $(0.53)$ & $*$ & -0.51 & $(0.22)$ & $*$ & -1.83 & $(0.74)$ & $*$ \\
\hline Mining & 7.64 & $(1.70)$ & $* * *$ & 2.99 & $(0.78)$ & $* * *$ & 10.63 & $(2.36)$ & $* * *$ \\
\hline Farming & -0.50 & $(0.94)$ & & -0.19 & $(0.36)$ & & -0.69 & $(1.30)$ & \\
\hline Persistent population loss & 2.10 & $(0.77)$ & $* *$ & 0.82 & $(0.33)$ & $*$ & 2.93 & $(1.08)$ & $* *$ \\
\hline Opioid prescribing (logged) & 2.42 & $(0.31)$ & $* * *$ & 5.09 & $(0.59)$ & $* * *$ & 7.51 & $(0.70)$ & $* * *$ \\
\hline
\end{tabular}

$\mathrm{SE}=$ standard error; $* * * \mathrm{p}<.001 ; * * \mathrm{p}<.01 ; * \mathrm{p}<.05$; two-tailed tests

All models control for county age composition (2000), percent non-Hispanic white (2000), and percent veterans (2000). Economic distress, family distress, and opioid prescribing (logged) are standardized to have a mean of 0 and standard deviation of 1 .

Direct effect: effect of the change within the county, ignoring spillover effects

Indirect effect: spillover effect

Total effect: sum of the direct and indirect effects 
Table D4. Margins from Spatial Lag of DV \& Spatial Lag of IVs \& Spatially Autoregressive Error Model (Model 3 in Table D1)

\begin{tabular}{|c|c|c|c|c|c|c|c|c|c|}
\hline & \multicolumn{3}{|c|}{ Direct Effect } & \multicolumn{3}{|c|}{ Indirect Effect } & \multicolumn{3}{|c|}{ Total Effect } \\
\hline & Est. & S.E. & & Est. & S.E. & & Est. & S.E. & \\
\hline \multicolumn{10}{|c|}{ Urban-Rural Continuum (ref=Large metro) } \\
\hline Small metro & -2.08 & $(0.73)$ & $* *$ & -0.76 & $(0.29)$ & $* *$ & -2.84 & $(1.00)$ & $* *$ \\
\hline Large nonmet, adjacent to met & -3.79 & $(0.66)$ & $* * *$ & -1.38 & $(0.32)$ & $* * *$ & -5.17 & $(0.91)$ & $* * *$ \\
\hline Large nonmet, not adjacent to met & -4.35 & $(0.83)$ & $* * *$ & -1.59 & $(0.37)$ & $* * *$ & -5.93 & $(1.12)$ & $* * *$ \\
\hline Rural & -5.78 & $(1.04)$ & $* * *$ & -2.11 & $(0.46)$ & $* * *$ & -7.88 & $(1.38)$ & $* * *$ \\
\hline Economic distress, 2000 & 3.88 & $(0.53)$ & $* * *$ & -1.61 & $(0.62)$ & $*$ & 2.28 & $(0.71)$ & $* *$ \\
\hline Family distress, 2000 & 2.61 & $(0.47)$ & $* * *$ & 0.95 & $(0.24)$ & $* * *$ & 3.57 & $(0.66)$ & $* * *$ \\
\hline \multicolumn{10}{|l|}{$\begin{array}{l}\text { Economic dependence, } 2004 \text { (ref=non- } \\
\text { specialized) }\end{array}$} \\
\hline Services & 3.98 & $(0.81)$ & $* * *$ & 1.45 & $(0.39)$ & $* * *$ & 5.43 & $(1.14)$ & $* * *$ \\
\hline Public sector & -0.52 & $(0.82)$ & & -0.19 & $(0.30)$ & & -0.72 & $(1.12)$ & \\
\hline Manufacturing & -1.22 & $(0.53)$ & * & -0.44 & $(0.20)$ & * & -1.66 & $(0.72)$ & * \\
\hline Mining & 6.54 & $(1.72)$ & $* * *$ & 2.39 & $(0.70)$ & $* *$ & 8.93 & $(2.33)$ & $* * *$ \\
\hline Farming & -0.32 & $(0.97)$ & & -0.12 & $(0.35)$ & & -0.44 & $(1.33)$ & \\
\hline Persistent population loss & 2.01 & $(0.78)$ & * & 0.73 & $(0.32)$ & * & 2.75 & $(1.08)$ & * \\
\hline Opioid prescribing (logged) & 2.38 & $(0.31)$ & $* * *$ & 4.92 & $(0.64)$ & $* * *$ & 7.30 & $(0.78)$ & $* * *$ \\
\hline
\end{tabular}

$\mathrm{SE}=$ standard error; $* * * \mathrm{p}<.001 ; * * \mathrm{p}<.01 ; * \mathrm{p}<.05 ;$ two-tailed tests

All models control for county age composition (2000), percent non-Hispanic white (2000), and percent veterans (2000). Economic distress, family distress, and opioid prescribing (logged) are standardized to have a mean of 0 and standard deviation of 1.

Direct effect: effect of the change within the county, ignoring spillover effects

Indirect effect: spillover effect

Total effect: sum of the direct and indirect effects 
Table D5. Results from Spatial Regression Models (with State Fixed Effects) Predicting Non-Hispanic White Drug Mortality Rates, 2014-16

\begin{tabular}{|c|c|c|c|c|c|c|c|c|c|}
\hline & \multicolumn{3}{|c|}{ Model 1} & \multicolumn{3}{|c|}{ Model 2} & \multicolumn{3}{|c|}{ Model 3} \\
\hline & Est. & S.E. & & Est. & S.E. & & Est. & S.E. & \\
\hline Intercept & 16.37 & $(1.72)$ & $* * *$ & 15.77 & $(1.68)$ & $* * *$ & 14.88 & $(1.76)$ & $* * *$ \\
\hline \multicolumn{10}{|l|}{ Urban-Rural Continuum (ref=Large metro) } \\
\hline Small metro & -2.53 & $(0.69)$ & $* * *$ & -1.92 & $(0.69)$ & $* *$ & -1.70 & $(0.69)$ & $*$ \\
\hline Large nonmet, adjacent to met & -4.17 & $(0.64)$ & $* * *$ & -3.75 & $(0.63)$ & $* * *$ & -3.54 & $(0.63)$ & $* * *$ \\
\hline Large nonmet, not adjacent to met & -5.22 & $(0.80)$ & $* * *$ & -4.20 & $(0.81)$ & $* * *$ & -3.80 & $(0.83)$ & $* * *$ \\
\hline Rural & -6.12 & $(1.02)$ & $* * *$ & -5.55 & $(1.02)$ & $* * *$ & -5.20 & $(1.02)$ & $* * *$ \\
\hline Economic distress, 2000 & 2.85 & $(0.44)$ & $* * *$ & 3.57 & $(0.51)$ & $* * *$ & 3.44 & $(0.51)$ & $* * *$ \\
\hline Family distress, 2000 & 2.71 & $(0.45)$ & $* * *$ & 2.53 & $(0.45)$ & $* * *$ & 2.67 & $(0.46)$ & $* * *$ \\
\hline \multicolumn{10}{|l|}{$\begin{array}{l}\text { Economic dependence, } 2004(\mathrm{ref}=\text { non- } \\
\underline{\text { specialized })}\end{array}$} \\
\hline Services & 2.92 & $(0.81)$ & $* * *$ & 2.97 & $(0.80)$ & $* * *$ & 2.91 & $(0.80)$ & $* * *$ \\
\hline Public sector & -1.58 & $(0.76)$ & $*$ & -1.35 & $(0.76)$ & & -1.18 & $(0.76)$ & \\
\hline Manufacturing & -1.20 & $(0.52)$ & $*$ & -1.33 & $(0.52)$ & $*$ & -1.22 & $(0.52)$ & $*$ \\
\hline Mining & 6.22 & $(1.67)$ & $* * *$ & 6.42 & $(1.66)$ & $* * *$ & 5.81 & $(1.67)$ & $* * *$ \\
\hline Farming & 0.70 & $(0.97)$ & $* * *$ & 0.60 & $(0.97)$ & & 0.60 & $(0.98)$ & \\
\hline Persistent population loss & 1.97 & $(0.75)$ & $* *$ & 2.10 & $(0.74)$ & ** & 2.05 & $(0.75)$ & $* *$ \\
\hline Opioid prescribing (logged) & 1.88 & $(0.30)$ & $* * *$ & 1.97 & $(0.30)$ & $* * *$ & 1.92 & $(0.30)$ & $* * *$ \\
\hline Spatial lag of drug mortality rate( $\left.\mathrm{Wy}_{\text {mort }}\right)$ & 0.27 & $(0.04)$ & $* * *$ & 0.27 & $(0.04)$ & $* * *$ & 0.30 & $(0.04)$ & $* * *$ \\
\hline Spatial lag of economic distress $\left(\mathrm{Wx}_{\mathrm{econ}}\right)$ & & & & -2.55 & $(0.59)$ & $* * *$ & -2.59 & $(0.60)$ & $* * *$ \\
\hline Spatial lag of opioid prescribing $\left(\mathrm{Wx}_{\mathrm{rx}}\right)$ & & & & 1.99 & $(0.66)$ & ** & 1.85 & $(0.67)$ & $* *$ \\
\hline Spatial error $(\mathrm{I}-p \mathrm{~W})^{-1} \varepsilon$ & & & & & & & 0.08 & $(0.06)$ & \\
\hline Pseudo $\mathrm{R}^{2}$ & 0.3784 & & & 0.3857 & & & 0.3824 & & \\
\hline
\end{tabular}

$\mathrm{SE}=$ standard error; $* * * \mathrm{p}<.001 ; * * \mathrm{p}<.01 ; * \mathrm{p}<.05 ;$ two-tailed tests

All models control for state fixed effects, county age composition (2000), percent non-Hispanic white (2000), and percent veterans (2000). Economic distress,

family distress, and opioid prescribing (logged) are standardized to have a mean of 0 and standard deviation of 1 .

Model 1: includes spatial lag of the dependent variable

Model 2: includes spatial lag of the dependent variable and spatial lags for economic distress and opioid prescribing

Model 3: includes spatial lag of the dependent variable, spatial lags for economic distress and opioid prescribing, and a spatially autoregressive error 
Table D6. Margins from Spatial Lag of DV Model with State Fixed Effects (Model 1 in Table D5)

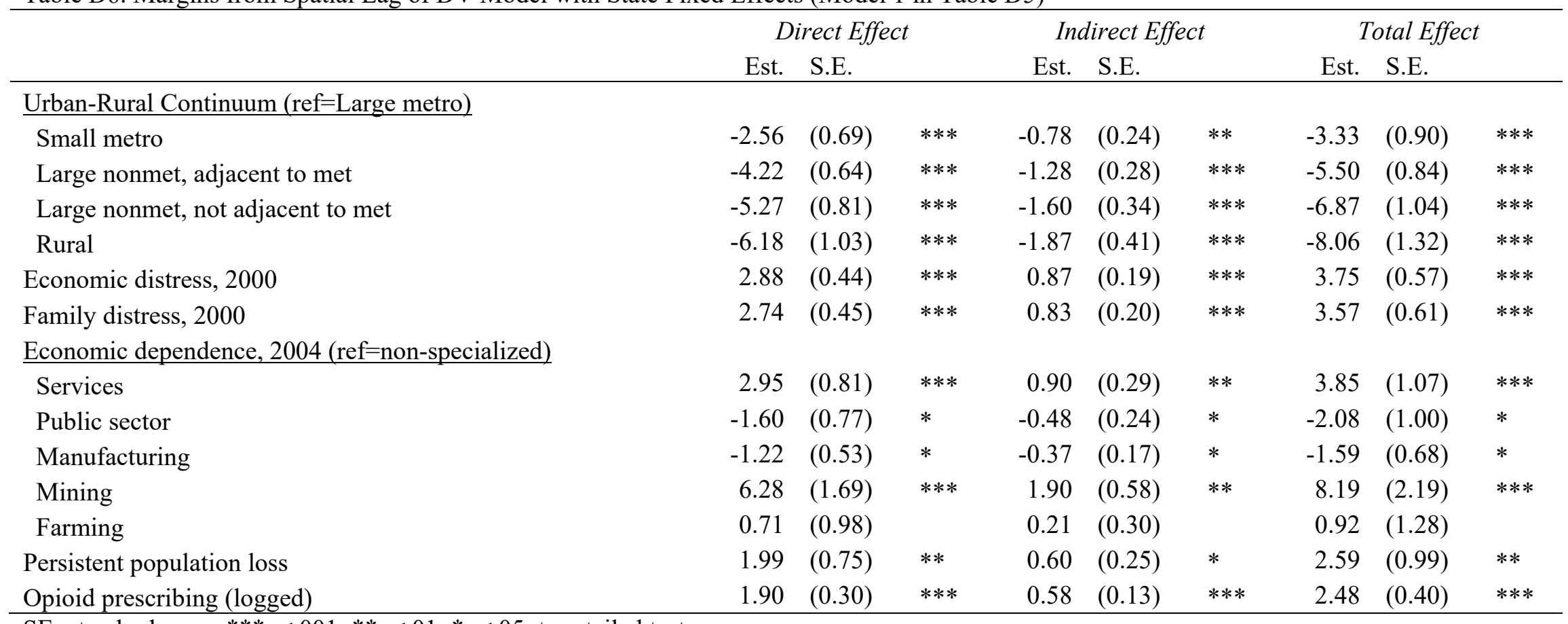

$\mathrm{SE}=$ standard error; $* * * \mathrm{p}<.001 ; * * \mathrm{p}<.01 ; * \mathrm{p}<.05 ;$ two-tailed tests

All models control for state fixed effects, county age composition (2000), percent non-Hispanic white (2000), and percent veterans (2000).

Economic distress, family distress, and opioid prescribing (logged) are standardized to have a mean of 0 and standard deviation of 1 .

Direct effect: effect of the change within the county, ignoring spillover effects

Indirect effect: spillover effect

Total effect: sum of the direct and indirect effects 
Table D7. Margins from Spatial Lag of DV \& Spatial Lag of IVs Model with State Fixed Effects (Model 2 in Table D5)

\begin{tabular}{|c|c|c|c|c|c|c|c|c|c|}
\hline & \multicolumn{3}{|c|}{ Direct Effect } & \multicolumn{3}{|c|}{ Indirect Effect } & \multicolumn{3}{|c|}{ Total Effect } \\
\hline & Est. & S.E. & & Est. & S.E. & & Est. & S.E. & \\
\hline \multicolumn{10}{|c|}{ Urban-Rural Continuum (ref=Large metro) } \\
\hline Small metro & -1.94 & $(0.70)$ & $* *$ & -0.58 & $(0.23)$ & * & -2.52 & $(0.91)$ & $* *$ \\
\hline Large nonmet, adjacent to met & -3.79 & $(0.64)$ & $* * *$ & -1.14 & $(0.28)$ & $* * *$ & -4.93 & $(0.84)$ & $* * *$ \\
\hline Large nonmet, not adjacent to met & -4.25 & $(0.82)$ & $* * *$ & -1.27 & $(0.32)$ & $* * *$ & -5.52 & $(1.06)$ & $* * *$ \\
\hline Rural & -5.60 & $(1.02)$ & $* * *$ & -1.68 & $(0.40)$ & $* * *$ & -7.28 & $(1.31)$ & $* * *$ \\
\hline Economic distress, 2000 & 3.50 & $(0.50)$ & $* * *$ & -1.78 & $(0.60)$ & $* *$ & 1.73 & $(0.66)$ & $* *$ \\
\hline Family distress, 2000 & 2.56 & $(0.46)$ & $* * *$ & 0.77 & $(0.21)$ & $* * *$ & 3.33 & $(0.62)$ & $* * *$ \\
\hline \multicolumn{10}{|c|}{ Economic dependence, 2004 (ref=non-specialized) } \\
\hline Services & 3.00 & $(0.81)$ & $* * *$ & 0.90 & $(0.30)$ & $* *$ & 3.90 & $(1.06)$ & $* * *$ \\
\hline Public sector & -1.37 & $(0.77)$ & & -0.41 & $(0.24)$ & & -1.77 & $(0.99)$ & \\
\hline Manufacturing & -1.34 & $(0.52)$ & * & -0.40 & $(0.17)$ & $*$ & -1.74 & $(0.68)$ & $*$ \\
\hline Mining & 6.48 & $(1.67)$ & $* * *$ & 1.94 & $(0.59)$ & $* * *$ & 8.43 & $(2.16)$ & $* * *$ \\
\hline Farming & 0.61 & $(0.98)$ & & 0.18 & $(0.30)$ & & 0.79 & $(1.27)$ & \\
\hline Persistent population loss & 2.12 & $(0.75)$ & $* *$ & 0.64 & $(0.25)$ & * & 2.76 & $(0.98)$ & $* *$ \\
\hline Opioid prescribing (logged) & 2.06 & $(0.30)$ & $* * *$ & 2.83 & $(0.69)$ & $*$ & 4.89 & $(0.82)$ & $* * *$ \\
\hline
\end{tabular}

$\mathrm{SE}=$ standard error; $* * * \mathrm{p}<.001 ; * * \mathrm{p}<.01 ; * \mathrm{p}<.05 ;$ two-tailed tests

All models control for state fixed effects, county age composition (2000), percent non-Hispanic white (2000), and percent veterans (2000).

Economic distress, family distress, and opioid prescribing (logged) are standardized to have a mean of 0 and standard deviation of 1 .

Direct effect: effect of the change within the county, ignoring spillover effects

Indirect effect: spillover effect

Total effect: sum of the direct and indirect effects 
Table D8. Margins from Spatial Lag of DV \& Spatial Lag of IVs \& Spatially Autoregressive Error Model with State Fixed Effects (Model 3 in Table D5)

\begin{tabular}{|c|c|c|c|c|c|c|c|c|c|}
\hline & \multicolumn{3}{|c|}{ Direct Effect } & \multicolumn{3}{|c|}{ Indirect Effect } & \multicolumn{3}{|c|}{ Total Effect } \\
\hline & Est. & S.E. & & Est. & S.E. & & Est. & S.E. & \\
\hline \multicolumn{10}{|c|}{ Urban-Rural Continuum (ref=Large metro) } \\
\hline Small metro & -1.72 & $(0.70)$ & $*$ & -0.59 & $(0.26)$ & $*$ & -2.31 & $(0.94)$ & $*$ \\
\hline Large nonmet, adjacent to met & -3.58 & $(0.64)$ & $* * *$ & -1.22 & $(0.30)$ & $* * *$ & -4.80 & $(0.87)$ & $* * *$ \\
\hline Large nonmet, not adjacent to met & -3.84 & $(0.84)$ & $* * *$ & -1.31 & $(0.34)$ & $* * *$ & -5.15 & $(1.12)$ & $* * *$ \\
\hline Rural & -5.27 & $(1.03)$ & $* * *$ & -1.79 & $(0.43)$ & $* * *$ & -7.06 & $(1.36)$ & $* * *$ \\
\hline Economic distress, 2000 & 3.37 & $(0.50)$ & $* * *$ & -1.80 & $(0.62)$ & $* *$ & 1.57 & $(0.71)$ & $*$ \\
\hline Family distress, 2000 & 2.71 & $(0.46)$ & $* * *$ & 0.92 & $(0.23)$ & $* * *$ & 3.63 & $(0.64)$ & $* * *$ \\
\hline \multicolumn{10}{|c|}{ Economic dependence, 2004 (ref=non-specialized) } \\
\hline Services & 2.95 & $(0.81)$ & $* * *$ & 1.00 & $(0.33)$ & $* *$ & 3.95 & $(1.10)$ & $* * *$ \\
\hline Public sector & -1.19 & $(0.77)$ & & -0.41 & $(0.27)$ & & -1.60 & $(1.03)$ & \\
\hline Manufacturing & -1.24 & $(0.52)$ & $*$ & -0.42 & $(0.19)$ & $*$ & -1.66 & $(0.70)$ & $*$ \\
\hline Mining & 5.89 & $(1.69)$ & $* * *$ & 2.00 & $(0.64)$ & $* * *$ & 7.89 & $(2.25)$ & $* * *$ \\
\hline Farming & 0.61 & $(0.99)$ & & 0.21 & $(0.34)$ & & 0.82 & (1.33) & \\
\hline Persistent population loss & 2.08 & $(0.76)$ & $* *$ & 0.71 & $(0.28)$ & $*$ & 2.78 & $(1.02)$ & $* *$ \\
\hline Opioid prescribing (logged) & 2.02 & $(0.31)$ & $* * *$ & 2.80 & $(0.75)$ & $* * *$ & 4.82 & $(0.89)$ & $* * *$ \\
\hline
\end{tabular}

$\mathrm{SE}=$ standard error; $* * * \mathrm{p}<.001 ; * * \mathrm{p}<.01 ; * \mathrm{p}<.05 ;$ two-tailed tests

All models control for state fixed effects, county age composition (2000), percent non-Hispanic white (2000), and percent veterans (2000).

Economic distress, family distress, and opioid prescribing (logged) are standardized to have a mean of 0 and standard deviation of 1.

Direct effect: effect of the change within the county, ignoring spillover effects

Indirect effect: spillover effect

Total effect: sum of the direct and indirect effects 


\section{APPENDIX E: Supplemental Analyses}

Table E1. Results from Multivariate Random Effects (Multilevel) Negative Binomial Models of Non-Hispanic White Drug Death Count, $2014-16$

\begin{tabular}{|c|c|c|c|c|}
\hline & $\begin{array}{c}\text { Model } 1 \\
\text { IDR }(95 \% \mathrm{CI})\end{array}$ & $\begin{array}{c}\text { Model } 2 \\
\text { IDR }(95 \% \mathrm{CI})\end{array}$ & $\begin{array}{c}\text { Model } 3 \\
\text { IDR }(95 \% \mathrm{CI})\end{array}$ & $\begin{array}{c}\text { Model } 4 \\
\text { IDR }(95 \% \mathrm{CI})\end{array}$ \\
\hline \multicolumn{5}{|l|}{ Urban-Rural Continuum (ref=Large } \\
\hline Small metro & $0.91 * * *(0.86$ to 0.96$)$ & $0.86^{* * *}(0.82$ to 0.90$)$ & $0.87 * * *(0.83$ to 0.92$)$ & $0.87 * * *(0.83$ to 0.92$)$ \\
\hline Large nonmet, adjacent to met & $0.89 * * *(0.86$ to 0.94$)$ & $0.83 * * *(0.79$ to 0.86$)$ & $0.84 * * *(0.81$ to 0.88$)$ & $0.84 * * *(0.81$ to 0.88$)$ \\
\hline Large nonmet, not adjacent to met & $0.89 * * *(0.84$ to 0.94$)$ & $0.78 * * *(0.74$ to 0.83$)$ & $0.79 * * *(0.75$ to 0.83$)$ & $0.79 * * *(0.75$ to 0.84$)$ \\
\hline Rural & $0.77 * * *(0.71$ to 0.82$)$ & $0.71 * * *(0.66$ to 0.76$)$ & $0.76 * * *(0.71$ to 0.82$)$ & $0.77 * * *(0.72$ to 0.83$)$ \\
\hline Economic distress, 2000 & & $1.13 * * *(1.10$ to 1.16$)$ & $1.09^{* * *}(0.106$ to 1.12$)$ & $1.09 * * *(1.05$ to 1.13$)$ \\
\hline Family distress, 2000 & & $1.20 * * *(1.17$ to 1.23$)$ & $1.16^{* * *}(1.13$ to 1.19$)$ & $1.16^{* * *}(1.13$ to 1.19$)$ \\
\hline \multicolumn{5}{|l|}{$\begin{array}{l}\text { Economic dependence, } 2004 \text { (ref=non- } \\
\text { specialized) }\end{array}$} \\
\hline Farming & & $1.03(0.95$ to 1.12$)$ & $1.06(0.98$ to 1.14$)$ & $1.05(0.97$ to 1.14$)$ \\
\hline Mining & & $1.24 * * *(1.13$ to 1.35$)$ & $1.21 * * *(1.11$ to 1.31$)$ & $1.20 * * *(1.10$ to 1.31$)$ \\
\hline Manufacturing & & $0.96^{*}(0.92$ to 0.99$)$ & $0.96 *(0.92$ to 0.99$)$ & $0.96 *(0.92$ to 0.99$)$ \\
\hline Public sector & & $0.89 * * *(0.85$ to 0.94$)$ & $0.90 * * *(0.85$ to 0.95$)$ & $0.91 * * *(0.86$ to 0.95$)$ \\
\hline Services & & $1.12 * * *(1.06$ to 1.18$)$ & $1.10 * * *(1.04$ to 1.15$)$ & $1.10^{* * *}(1.05$ to 1.16$)$ \\
\hline Persistent population loss & & $1.08^{* *}(1.03$ to 1.14$)$ & $1.06 *(1.01$ to 1.12$)$ & $1.07 *(1.01$ to 1.12$)$ \\
\hline Opioid prescribing (logged) & & & $1.10 * * *(1.08$ to 1.13$)$ & $1.11 * * *(1.08$ to 1.14$)$ \\
\hline $\begin{array}{l}\text { Avg. opioid prescribing of neighboring } \\
\text { counties }\end{array}$ & & & $1.10 * * *(1.07$ to 1.12$)$ & $1.10 * * *(1.07$ to 1.12$)$ \\
\hline High fentanyl encounter state & & & $1.30 * *(1.11$ to 1.51$)$ & $1.29^{* *}(1.12$ to 1.50$)$ \\
\hline Intercept & $-8.30(0.05)^{* * *}$ & $-8.28(0.04)^{* * *}$ & $-8.36(0.04)^{* * *}$ & $-8.36(0.04)^{* * *}$ \\
\hline \multicolumn{5}{|l|}{ Random Effects } \\
\hline Random Intercept & $0.108(0.024)^{* * *}$ & $0.069(0.016)^{* * *}$ & $0.040(0.010)^{* *}$ & $0.037(0.009)^{* * *}$ \\
\hline Economic distress, 2000 & & & & $0.003(0.001)^{* * *}$ \\
\hline Opioid prescribing & & & & $0.002(0.002)$ \\
\hline
\end{tabular}




\section{County N=3,047; State N=49}

$\mathrm{IDR}=$ Incidence Density Ratio; $\mathrm{CI}=$ confidence interval

${ }^{* * *} \mathrm{p}<.001 ; * * \mathrm{p}<.01 ;{ }^{*} \mathrm{p}<.05$; two-tailed tests

Coefficients from these models are interpreted as the percentage change in the mortality rate for a one-unit change in the predictor. All models

control for county age composition (2000), percent non-Hispanic white (2000), and percent veterans (2000). Coefficients represent the percentage difference in the drug mortality rate for a one-unit change in the predictor. Economic distress, family distress, opioid prescribing (logged), and average opioid prescribing of neighboring counties (logged) are standardized to have a mean of 0 and standard deviation of 1 . The coefficients for those variables represent the percentage difference in the mortality rate for a 1 standard deviation change in the predictor variable. 
Appendix Table E2. Results from Multivariate Random Effects Regression on Overall County-Level Drug Mortality Rates, 2014-16

\begin{tabular}{lrrr}
\hline & Est. & \multicolumn{1}{l}{ S.E. } \\
\hline Intercept & 23.66 & $(0.91)$ & $* * *$ \\
Urban-Rural Continuum (ref=Large metro) & & & \\
\hline Small metro & -2.39 & $(0.69)$ & $* * *$ \\
Large nonmet, adjacent to met & -3.23 & $(0.61)$ & $* * *$ \\
Large nonmet, not adjacent to met & -4.61 & $(0.71)$ & $* * *$ \\
Rural & -4.96 & $(0.80)$ & $* * *$ \\
Economic distress, 2000 & 3.17 & $(0.48)$ & $* * *$ \\
Family distress, 2000 & 2.25 & $(0.34)$ & $* * *$ \\
Economic dependence, 2004 (ref=non-specialized) & & & \\
Farming & -1.81 & $(0.76)$ & $*$ \\
Mining & 3.23 & $(1.07)$ & $* *$ \\
Manufacturing & -1.26 & $(0.52)$ & $*$ \\
Public sector & -1.80 & $(0.69)$ & $* *$ \\
Services & 2.32 & $(0.75)$ & $* *$ \\
Persistent population loss & 1.52 & $(0.60)$ & $*$ \\
Opioid prescribing (logged) & 2.41 & $(0.48)$ & $* * *$ \\
Avg. opioid prescribing of neighboring counties (logged) & 1.95 & $(0.29)$ & $* * *$ \\
High fentanyl encounter state & 5.97 & $(1.35)$ & $* * *$ \\
\hline Error Variance & & & \\
County-Level Variance & 104.64 & $(2.75)$ & $* * *$ \\
State-Level Variance & 20.07 & $(5.03)$ & $* * *$ \\
Economic Distress & 3.66 & $(1.35)$ & $* *$ \\
Opioid Prescribing & 1.14 & $(1.20)$ & \\
\hline Coun Ne3,047; State N-49 & & &
\end{tabular}

\section{County $\mathrm{N}=3,047$; State $\mathrm{N}=49$}

S.E. $=$ standard error; $* * * \mathrm{p}<.001 ; * * \mathrm{p}<.01 ; * \mathrm{p}<.05$; two-tailed tests

Multilevel model controls for county age composition (2000), percent non-Hispanic white (2000), and percent veterans (2000). Economic distress, family distress, opioid prescribing (logged), and average opioid prescribing of neighboring counties (logged) are standardized to have a mean of 0 and standard deviation of 1 . The coefficients for those variables represent the change in the mortality rate for a 1 standard deviation increase in the predictor variable. 